\title{
Can the Threat of Economic Sanctions Ensure the Sustainability of International Fisheries? An Experiment of a Dynamic Non-cooperative CPR Game with Uncertain Tipping Point
}

\author{
Selles Jules ${ }^{1,3,{ }^{*}}$, Bonhommeau Sylvain ${ }^{2}$, Guillotreau Patrice ${ }^{3}$, Vallee Thomas ${ }^{3}$
}

\begin{abstract}
1 1IFREMER (Institut Français de Recherche pour l'Exploitation de la MER), UMR MARBEC, Avenue Jean 9 Monnet, 7 BP171, 34203 Sète Cedex, France.

2 IFREMER, Délégation de l'Océan Indien, Rue Jean Bertho, BP 60, 97822, Le Port Cedex, France

${ }^{3}$ LEMNA, Université de Nantes, IEMN-IAE, Chemin de la Censive-du-Tertre, BP 52231, 44322, Nantes Cedex, France

*Corresponding author : Jules Selles, email address : jules.selles@gmail.com
\end{abstract}

\begin{abstract}
:
Complex dynamic systems such as common-pool resource systems can undergo a critical shift at a given threshold, the so-called tipping point, which potentially requires substantial changes from the management system. We present in this research a framed laboratory experiment design to examine how the threat of economic sanctions influences the strategic management of a common-pool resource. We use the context of the East Atlantic bluefin tuna international fishery as it has been the archetype of an overfished and mismanaged fishery until a dramatic reinforcement of its regulations followed the threat of a trade ban. We consider endogenous threats and examine their effects on cooperation through harvest decisions taken in the context of non-cooperative game theory in which cooperation could be sustained using a trigger strategy. Our experiment results show that the threat of economic sanctions fosters more cooperative behaviors, less over-exploitation, and a more precautionary management of resources, reducing the economic rent dissipation. This result is exacerbated when the location of the tipping point that triggers the economic sanction is uncertain. In order to avoid free-riding behaviors and foster the emergence of a self-enforcing agreement, we suggest to introduce economic sanctions, such as trade restrictions, associated with uncertain biological limit reference points.
\end{abstract}

Keywords : Common-pool resources, Experimental economics, Fisheries management, International fisheries, Policy making, Tipping points. 


\section{Introduction}

Like many natural resources, most of the fishery resources and more particularly the internationally shared fisheries fall into the category of common-pool resources (CPRs), which have faced management difficulties in addressing both conservation and economic challenges leading to over-exploitation (Pauly et al. 1998, Worm et al. 2009). In such CPR, the incentives to catch more resources and ignore the external costs are rational because "individuals" (i.e. states, companies etc.) receive benefits for themselves without bearing the social costs. Collectively, this rational individual behavior leads to the well-known tragedy of the commons (Gordon 1954, Hardin 1968).

Cooperation in CPR dilemmas has been most extensively studied in the context of internationally shared fisheries. Despite the legal obligation of States to cooperate within a Regional Fisheries Management Organisation (RFMO), States involved in international fisheries are not required to reach an agreement, or if an agreement is reached, it is not binding or enforceable (Munro et al. 2004). This sets non-cooperation to be the default option resulting from over-exploitation which is exacerbated in the case of international fisheries where many countries having divergent interests are involved, and where monitoring and management rules are notoriously difficult to enforce (Maguire et al. 2006, McWhinnie 2009, Cullis-Suzuki \& Pauly 2010, Teh \& Sumaila 2015). Understanding the strategic behavior of States in the collective decisionmaking process of international management bodies is critical (Munro 2004, Fulton et al. 2011). Theoretical work based on game theory has offered important insights about the outcomes of noncooperative harvests (e.g., Munro 1979, Levhari \& Mirman 1980, Clark 1980) and the gap to fill before reaching a conservative and cooperative agreement in the context of international fisheries (Bailey et al. 2010, Hannesson 2011, Pintassilgo et al. 2015 for an overview). A key message that emerges from this literature is that the prisoner's dilemma outcome persists and self-enforcing cooperative agreements are generally difficult to achieve because of the dynamic incentives to overharvest for fishers. However, much of this work has relied on the assumption of perfect information and excludes complex resource dynamics (e.g. non-linearities and multiple stable states) or potential shifts of the economic or natural environment (Bailey et al. 2010, Hannesson 2011).

Along with the theoretical development, economic experiments provide a means of evaluating strategic behavior in different institutional settings under controlled conditions by comparing direct observations with theoretical outcomes. Experimental research on CPR dilemmas has focused on repeated static ecological environments by focusing on the institutional aspects altering the strategic uncertainty ("social uncertainty" defined by Messick et al. 1988). Field and laboratory experiments have accumulated evidence that small groups of individuals 
could manage CPRs efficiently if they have the ability to communicate on a face-to-face basis, the autonomy to establish rules allocating rights and duties, and the capability to monitor and punish one another (overview in Ostrom 2006 and Poteete et al. 2010). This strand of literature has focused on small scale CPRs and disregarded large scale CPRs, such as international fisheries, where reaching agreements, monitoring, and enforcing rules are critical (Walker et al. 2000). Furthermore, the initial protocols have overlooked the dynamics of the social-ecological system in the resolution of CPR dilemmas, which have been considered only recently (e.g. Janssen et al. 2010, Cardenas 2013).

Large, sudden, and potentially persistent changes in the ecosystem dynamics have been extensively documented (e.g. Folke et al. 2004, Biggs et al. 2012 and the regime shift database http://www.regimeshifts.org). If the resilience of the system is eroded, trespassing on a tipping point can dramatically change the structure of a marine community for example, sometimes with irreversible impacts (hysteresis effects) on the productivity of the targeted species (e.g. the collapse of the North West Atlantic Cod Hutching \& Myers 1994, McCain et al. 2015). Socialecological systems and public opinion display the same kind of dynamics with critical transitions (Scheffer et al. 2009). Management systems can switch swiftly from a low to a high action level to deal with complex problems (e.g. the management of a common-pool resource) with new management frameworks and paradigms beyond a critical threshold (e.g. below some natural resource stock level, Scheffer et al. 2003).

This paper is inspired and motivated by the case of East Atlantic bluefin tuna (EABFT) international fishery discussed in other studies (Brasão et al. 2000). Awareness of public opinion by non-governmental organizations (NGO) played a major role in the shift of the management system of this highly migratory species (Fromentin et al. 2014). The threat of an economic sanction, namely a ban on foreign trade resulting from NGOs campaigns, triggered a shift in the management decisions adopted by the International Commission for the Conservation of Atlantic Tunas (ICCAT), thus reducing total annual catches from approximately 50,000 t between 1998 and 2007, to 10,000 $\mathrm{t}$ in 2010 consistent with the scientific advice (ICCAT 2012).

Our objective is to analyze how states, sharing a CPR, can coordinate their decisions when facing the threat of economic sanctions. In the present study, we rely on an experimental method to appraise the cooperation level in response to the introduction of endogenous tipping points. We performed a framed laboratory experiment mimicking the EABFT international fishery management context following the stylized representation of Brasão et al. (2000). We examine the strategic interaction between individuals in the context of non-cooperative game theory in which cooperation could be sustained by a trigger strategy. To this end, we limited communication to a non-binding pledge representing the difficulty to reach and agreements and enforce rules in the context of international fisheries. We compared three experimental treatments in which each 
101 subject played a dynamic CPR game by defining its own quotas as a State involved in the fishery

102 as a Contracting Party. In the different experimental treatments, some groups faced a simple 103 dynamic system while other groups faced tipping point triggering an economic sanction over all 104 subjects. In the latter, some groups faced a situation where the tipping point was known, whereas 105 the others faced a situation of uncertainty about the location of the tipping point. The threat of an 106 economic sanction considered in this study is latent and endogenously driven, i.e. triggered by 107 collective actions (aggregated catches).

108 Our experimental results show that the threat of an economic sanction fosters more 109 cooperative behaviors, less over-exploitation, and more precautionary management of the 110 resource reducing the dissipation of economic rents. This result is enhanced when the location of 111 the tipping point that triggers the economic sanction is uncertain.

\section{Review of literature}

114 The bulk of the experimental work on CPR dilemmas starts from the CPR baseline game of Ostrom 115 et al. (1994). They formulated a game as static framework, which is not appropriate to represent 116 the negative externalities associated with the dynamic patterns of natural stocks. The future exploitation of a fish stock depends on past exploitation levels. Consequently, the resource management problem must be set in a dynamic optimization context, making the task of achieving an optimal Pareto solution more complex.

This intuition has been confirmed in the case of a resource harvested under sole ownership (Moxnes 1998, Hey et al. 2009). Walker and Gardner (1992) extended the CPR baseline game by including path dependence and demonstrated that the sustainability of the resource is no longer maintained when the probability of resource collapse is linked to past harvest levels. In

124 addition, earlier depletion of the resource is clearly linked with the uncertainty level (Botelho et 125 al. 2014). A later work of Osés-Eraso et al. (2008) modified this game by implementing a finite126 horizon super-game, in which the extinction of the resource is a real threat. They found that the 127 likelihood of extinction is linked to whether the scarcity of the resource is exogenous or 128 endogenous, but early extinctions occurred irrespective of the initial scarcity of the resource. 129 Other experimental works have been conducted by Herr et al. (1997) and Mason and Phillips 130 (1997), setting participants as harvesters in a complex dynamic situation. Their current decision 131 did not influence the probability of destruction but changed the state of the resource and 132 economic opportunities. Both studies concluded that the individuals did not internalize future increased costs following the depletion of the resource and that the lack of cooperation is exacerbated when time-dependency is included in CPR dilemmas. 
Another kind of dynamic experiment has been developed by Fischer et al. (2004),

136

137

138

139

140

141

142

143

144

145

146

147

148

149

150

151

152

153

154

155

156

157

158

159

160

161

162

163

164

165

166

167

168 introducing the resource stock size into an intergenerational CPR game where the scarcity of the resource depends on the harvesting behavior of past generations. Although the size of the resource is common knowledge, individuals are unable to infer the actual level of scarcity and no correlation has been found between the resource stock size and the decisions adopted by the individuals.

While most research works assumed that the size and productivity of the resource are accurately known, the effects of environmental uncertainties have been introduced by repeated single-trial experiments (seminal works of Rapoport et al. 1992 and Budescu et al. 1995). In these experiments defined as threshold public goods experiments (overview in Chaudhuri 2011), individuals can harvest any amount of the CPR whose size parameters were randomly selected from known uniform probability distributions, but they receive a null payoff if the total quantity claimed exceeds the resource size (threshold). This strand of literature has demonstrated that higher uncertainty leads individuals to increase their appropriation of the shared resource significantly. More recently, public good games have also been studied in the frame of international climate negotiation to avoid catastrophic climate change in which uncertainty about the location of the threshold fostered the prisoners' dilemma outcome (e.g. Barret \& Danenberg 2012, 2014).

Complexity in the description of the social-ecological system has been introduced recently by combining spatial and temporal dimensions jointly (Moreno-Sánchez \& Maldonado 2010, Janssen et al., 2010, Castillo et al., 2011 Cardenas et al., 2013, Emery et al., 2015 a, b). Very few studies analyzed the consequences of regime shift in either the resource dynamics or the economic environment. Lindahl et al. (2016) showed that a user group manages a resource more efficiently when confronted with a latent abrupt change in the renewal rate of resources. Their analysis focused on communication, and demonstrated that the threat of reaching a critical tipping point triggers more effective communication within the group, enabling stronger commitment and an increase in efficiency despite the higher complexity. Schill et al. (2015) extended these results by introducing a risk to harvesting a resource with a probable threshold. They found that the threshold impact is observed only in situations where the likelihood of the latent shift is certain or high.

We contribute to this literature by exploring the effect of a tipping point affecting the economic conditions of the CPR dynamic game in which an individual's decisions are based on economic outcomes. In addition, we go further by analyzing how uncertainty about the timing of the tipping point, instead of its likelihood, affects decisions upon quotas. 


\section{Experimental setting}

170

171

172

173

174

175

176

177

178

179

180

181

182

183

184

185

186

187

188

189

190

191

192

193

194

195

196

197

198

199

200

201

\subsection{Experimental design}

Research questions are tested using a modified version of the experimental design of Mason \& Phillips (1997). This protocol defines a CPR request game (Budescu et al. 1995) in which a few firms harvest a resource in a dynamic context. We adapt their oligopoly model to a situation where the price is exogenously determined (constant price) and include a critical tipping point in the resource level which affects the economic conditions of the game. Following the methodology used in other complex ecological dynamic experiments (Schill et al. 2015, Lindahl et al. 2016), we introduce a non-neutral framework. According to the classification of Harrisson \& List (2004), this experiment falls within the category of "framed laboratory experiment". The task and information given to subjects correspond to a stylised representation of the actual context of the ICCAT Commission. The subjects are asked to define their harvest levels (quotas) for the East stock of Atlantic Bluefin. Subjects are only able to communicate through a non-binding pledge process: face to face communication is not allowed ${ }^{1}$. Moreover, to approximate an infinite time horizon super-game, the subjects do not know the number of rounds (years) to be played ${ }^{2}$; they only know the maximum duration. However, we make sure to end the experiment early enough to avoid potential end game effects.

We align our experiment onto the model of Hannesson (1997). The CPR biomass dynamics is modeled by a logistic growth (1) subject to harvest $\left(Y_{t}\right)$ in year $t$.

$$
B_{t+1}=G\left(B_{t}\right)-Y_{t}
$$

With $B_{t}$ thebiomass $\wedge$

$G\left(B_{t}\right)$ isthediscreteroundedversionofthelogisticgrowthmodel $\left(G\left(B_{t}\right)=\left[B_{t}\left[1+r\left(1-\frac{B_{t}}{K}\right)\right]\right]\right)$ presented to our subjects for simplicity. With $r$ and $K$ are the intrinsic growth rate of the population and the carrying capacity parameters respectively (Table 1).

We assume that the marginal cost of fishing ( $c$, Table 1 ) is inversely proportional to the size of the stock at any point in time ${ }^{2}$.The total cost depending on biomass $\left(C\left(B_{t}\right)\right)$ in period $t$ will then be:

$$
C\left(B_{t}\right)=\int_{B_{t}}^{G\left(B_{t-1}\right)} \frac{c}{x} d x=c\left[\ln \left(G\left(B_{t-1}\right)\right)-\ln \left(B_{t}\right)\right]
$$

At a given constant price ( $p$, Table 1$)$, the total profit $\left(\pi_{t}\right)$ obtained by all subjects $(i)$ in period $t$ with a fixed $\operatorname{cost}(\alpha$, Table 1$)$ associated with an endogenous resource threshold $B_{\text {lim. }}$. will be:

$$
\left\{\begin{array}{l}
\pi_{t}=p Y_{t}-C\left(B_{t}\right), \quad \text { for } B_{t} \geq B_{l i m} \\
\pi_{t}=p Y_{t}-C\left(B_{t}\right)-\alpha N, \text { for } B_{t}<B_{l i m}
\end{array}\right.
$$


With $N$ the number of participants, and assuming constant return to scale, the individual profit is $\pi_{i, t}=p y_{i, t}-C\left(B_{t}\right) \frac{y_{i, t}}{Y_{t}}$, for $B_{t}>B_{\text {lim }}$ and $\pi_{i, t}=p y_{i, t}-C\left(B_{t}\right) \frac{y_{i, t}}{Y_{t}}-\alpha$, for $B_{t} \leq B_{\text {lim }}$.

With y the individual harvest level of subject (i).

We introduce a fixed cost related to the resource size beyond the threshold level, $B_{\text {lim }}$ referring to the biomass limit reference points (FAO 1995), which corresponds to the stock size below which the recruitment has a high risk to be impaired and the stock is in danger of collapsing. This cost is a stylized representation of the critical effect of resource depletion. In the case of the EABFT fishery, this cost represents the effect of a ban on foreign trade. This fixed cost formulation follows the assumption of public good games with potential catastrophic effects from climate shifts (Milinski et al. 2008, Barret \& Danenberg 2012, 2014).

We introduce the resource growth model as discrete function to our subjects (Figure 1) and the associated profit evolution as depending on the stock and catch levels (Figure 2) for a selection of parameters that fit the context of EABFT (stylised version, Table 1). The minimum resource size allowing for reproduction is 3 units ( 1 unit is equivalent to $10^{4}$ tons) and the maximum resource size is set to 70 units. The maximum sustainable yield (MSY) is 3 units for a stock size between 28 to 42 units. The profit is maximum, greater than 100 units (1 monetary unit is equivalent to $10^{7} €$ ), when both the growth of the stock and catch levels are maximum, then it steadily decreases until the stock reaches the lowest values and becomes null at any catch level for a stock size of 10 units. In all treatments, the groups start with a stock size of 52 units and over a number of periods unknown to them, they harvest resource units restricted by an individual capacity constraint of 5 units $\left(\mathrm{y}_{\mathrm{i}, \mathrm{t}}=[0,1,2,3,4,5]\right)$. Groups are composed of 3 subjects sharing the same characteristics. This design follows the stylised representation from a game theory model of the EABFT fishery (Brasão et al. 2000).

Figure 1, Figure 2 and Table 1 around here

We introduce three experimental treatments to assess the cooperation in response to the introduction of three kinds of endogenous economic tipping points: i) base case without tipping point; ii) known tipping point and iii) uncertain (location) tipping point. In all three experimental treatments (T0, T1 and T2 in Table 2), a group of subjects defines a catch harvest for their own EABFT fishery. The only aspects that differ between treatments are the nature of the threshold $\left(B_{l i m}\right)$. The uncertainty surrounding the latent endogenous shift differs from the risk evaluated by Schill et al. (2015). In our case the uncertainty focuses on the position of the threshold, and not on its existence. The third treatment (T2) introduces uncertainty around the position of the threshold 
value $B_{\text {lim }}$ which is drawn within a $40 \%$ uniform uncertainty $\left[B_{\text {lim }}^{\min }, B_{\text {lim }}^{\max }\right]$ centered around the value of $B_{l i m}{ }^{4}$.

\subsection{Experimental procedure}

Table 2 around here

The experiment was conducted at the experimental laboratory of the University of Montpellier (LEEM) with a total of 51 subjects coming from the undergraduate student population in May 2017. The experiment was conducted through a computer-based approach realized with the oTree software (Chen et al., 2016). Each experimental session lasted a maximum of two hours with two repetitions of the game for the same group of subjects (phases). Participants received a show-up fee of $6 €$ and the average earnings during the experiments were $2.94 €$, paid privately at the end of the experiment (see supplementary material Appendix A for a flow chart of experimental steps).

When the subjects arrived, they signed a consent form and were randomly assigned to a group of 3 subjects with the instructions to read (supplementary material Appendix B). They were told that each subject represented a country, and that together with the two other participants of their group, they had access to the stock of the East Atlantic bluefin tuna, a common renewable resource, from which they had to decide the amount of allowable harvest for their fishery at the beginning of each round (each year), before deciding privately in a further step what would be their own harvest decision. Subjects were told that the experiment would end either when the stock is depleted or when the experimenter decides to stop it, but the exact end-period was unknown to them. They began with a capital of 50 monetary units and were paid proportionally to their accumulated profit during the experiment with a rate of 1 unit equal to $0.05 €$ plus an additional revenue of $0.2 €$ for correct belief elicitation. Belief elicitation constitutes a guess of the expectation of other subjects' behavior (harvest level). They received payment for only one phase of the experiment randomly chosen and unknown to them. No direct communication (face to face) between subjects was allowed.

Before the start of the experiment, the subjects were asked to fill out a form to inform their identity and if they were concerned or involved with the subject of the study (supplementary material Appendix C), and then they were tested for their understanding of the instructions, i.e. resource dynamics and profits (3 questions, supplementary material Appendix C). Any remaining question was answered by the experimenter. For each round, players received information about the resource state from which a profit table is derived and updated for every round (supplementary material Appendix D). They were also informed about the percentage variation of the biomass for the next year through a variation table depending on the harvest level of the 
group (supplementary material Appendix D). Furthermore, the mean resource level at MSY (35 units) was also indicated with the resource status and defined as a non-binding objective for the group. This information creates a collective reference point in order to facilitate the understanding of the long-term sustainable resource level maximizing the growth of the resource. Therefore, optimizing the use of the resource can focus on the mere level ensuring maximum profits. This information is necessary to concentrate the problem on the resource sharing issue, and not on the optimization of a non-linear dynamic system which proved to be a complex problem (Moxnes 1998 and Hey et al. 2009).

On top of deciding their harvest level, the subjects had to guess the sum of harvest units they expected the other players would harvest in each period from 0 to 10 units. Belief elicitation was incentivized with a payoff of $0.2 €$ for good prediction and allowed examining the source of deviations from theoretical predictions. Thereafter, participants pledged an amount of catch they would harvest individually. It was common knowledge that these declarations were non-binding but would be communicated to the group. After these declarations were revealed, the participants chose simultaneously their actual harvest level for the round (year). At the end of the round, the participants were then informed about everyone's decisions for the round and they were given their cumulated profit and the track records of the total catch, profit and own decision during the game. They also had access to a projection of the future resource status assuming a constant harvest level scenario defined at the current harvest level (supplementary material Appendix E). At the end of the experiment, participants were informed about their cumulated profit. They were also asked to indicate, on a five-point Likert scale, to what extent they understood the resource dynamics and the cooperation level of their group during the experiment.

\subsection{Formulating hypothesis}

To formulate the research hypotheses, we rely on the analysis of an indefinite time horizon supergame made by Hannesson (1997). The subjects know that the game will end at some point but not when. At every round of the game, each subject $i$ in the group has an individual perception about whether or not the game would last another round (sort of a discount factor), which we denote $\delta_{i}$ (Fudenberg and Tirole 1998). The implication of these subjective probabilities defines the equilibrium conditions of the game.

During the experiment, participants receive updates on the stock level $B_{t}$ and on their available profit at the beginning of each period. They also know if someone deviates from its proposition and if a participant behaves as a selfish agent. Thereby, each participant conditions her/his strategy on past and current resource and profit levels. On the basis of this information, each participant plays a Markov strategy (Maskin and Tirole 2001). Because players are 
symmetric (same cost functions), we only consider equal sharing equilibria (equal share of the resource) in which each subject gets $\frac{1}{N}$ of the total profits of each period.

Cooperative strategy could be sustained by a trigger strategy in the game. Considering the case without tipping point, if one of the participants deviates from the optimal solution, she/he would gain more in the current period and would then be punished afterwards. Other players would retaliate by fishing down the stock in the following periods until further depletion becomes unprofitable. Such a scenario results in resource depletion until the marginal cost of fish caught $(c)$ is equal to the marginal revenue, i.e. the fish price ( $p$, Eq. 3). The size of the stock resulting from such a strategy (trigger) is then:

$$
B_{\text {trig }}=\frac{c}{p}
$$

Otherwise, the optimal solution could be sustained as a Markov perfect strategy if the defection is not profitable. The net present value of the cooperative strategy $N P V_{\text {coop }}$ for infinite horizon is:

$$
N P V_{\text {coop }}=\frac{\pi_{0}}{N}+\frac{\pi_{o p t}}{N} \frac{\delta}{1-\delta}
$$

With an initial stock of 52 units ( $10^{4}$ tons), the optimal outcome is obtained by harvesting the stock until the optimal level $B_{\text {opt }}$ is reached in the first period, each subject gaining $\frac{\pi_{0}}{N}$. In each subsequent period, the group harvests the sustainable yields $\left(G\left(B_{t}\right)\right)$ until the stock reaches its optimal size $B_{\text {opt }}$ and each subject obtains $\frac{\pi_{o p t}}{N}$.

The net present value $\left(N P V_{\text {non-coop }}\right)$ of the non-cooperative strategy is defined for a participant who deviates from the cooperative solution and which is then punished by all other participants playing non-cooperatively afterwards and forever ${ }^{5}$.

$$
\mathrm{NPV}_{\text {non-coop }}=\frac{\pi_{0}}{\mathrm{~N}}+\frac{\pi_{\mathrm{opt}}}{\mathrm{N}} \delta+\pi_{\mathrm{dev}} \delta+\frac{\pi_{\mathrm{pun}}}{\mathrm{N}} \delta^{2}+\frac{\pi_{\text {trig }}}{\mathrm{N}} \frac{\delta^{3}}{1-\delta}
$$

With $\pi_{\text {opt }}=\mathrm{p}\left(\mathrm{G}\left(\mathrm{B}_{\mathrm{opt}}\right)-\mathrm{B}_{\mathrm{opt}}\right)-\mathrm{c}\left[\ln \left(\mathrm{G}\left(\mathrm{B}_{\mathrm{opt}}\right)\right)-\ln \left(\mathrm{B}_{\mathrm{opt}}\right)\right]$;

$\pi_{\mathrm{dev}}=\mathrm{p}\left(\mathrm{B}_{\mathrm{opt}}-\left(\mathrm{B}_{\mathrm{dev}}\right)\right)-\mathrm{c}\left[\ln \left(\mathrm{B}_{\mathrm{opt}}\right)-\ln \left(\mathrm{B}_{\mathrm{dev}}\right)\right] ;$

$\pi_{\text {pun }}=\mathrm{p}\left(\mathrm{G}\left(\mathrm{B}_{\text {dev }}\right)-\mathrm{B}_{\text {trig }}\right)-\mathrm{c}\left[\ln \left(\mathrm{G}\left(\mathrm{B}_{\text {dev }}\right)\right)-\ln \left(\mathrm{B}_{\text {trig }}\right)\right]$ and

$\pi_{\text {trig }}=p\left(G\left(B_{\text {trig }}\right)-B_{\text {trig }}\right)-c\left[\ln \left(G\left(B_{\text {trig }}\right)\right)-\ln \left(B_{\text {trig }}\right)\right]$.

In the first two periods, the defector gets the same profit as in the cooperative solution, as all other participants play cooperatively, and in addition the defector gets the profit of driving the stock down unilaterally to the deviation level $B_{d e v}\left(\right.$ get $\left.\pi_{d e v}\right)$. In the third and all later periods, he will be punished by all other agents playing non-cooperatively, driving the stock down from $B_{d e v}$ to the trigger strategy level $B_{\text {trig }}\left(10\right.$ units) and gets the profit from the punishment $\frac{\pi_{p u n}}{N}$. Then, the defector gets only the profit obtained in the non-cooperative solution by harvesting the trigger biomass level $B_{\text {tigr }}$ and obtaining the profit $\frac{\pi_{\text {trig }}}{N}$. 
The trigger strategy forms a subgame perfect equilibrium, if the defection is not profitable, $N P V_{\text {coop }}>N P V_{\text {non-coop }}{ }^{6}$, which gives the condition:

$$
\pi_{\text {opt }}>\frac{1-\delta}{\delta} N \pi_{\text {dev }}+(1-\delta) \pi_{\text {pun }}+\delta \pi_{\text {trig }}
$$

As $\delta$ tends to 1 (i.e. the discount rate tends to 0 ) meaning a higher preference for future, defection will never be profitable (by definition equation 7 becomes $\pi_{\text {opt }}>\pi_{\text {trig }}$, see supplementary material Appendix F for the relationship between $B_{\text {opt }}$ and $\delta$ ). In other words, the loss from punishment will always outweigh the gains from defecting. As $\delta$ becomes inferior to 1 , the temporary gains from defecting may outweigh the long-term profit of playing cooperatively. Moreover, the temptation of defecting decreases with higher fishing costs. A higher cost of fishing (c) increases the likelihood of a cooperative solution (the demonstration can be found in Hanneson 1997).

The introduction of a fixed cost triggered by fishing down the stock below the threshold $B_{\text {lim }}$ changes the size of the stock resulting from non-cooperative strategy $B_{\text {trig }}$ from a level where further depletion becomes unprofitable (since the marginal cost of fish caught is equal to the price) to the level of the threshold $B_{\text {lim }}$ which is by definition superior to $B_{\text {trig }}\left(B_{\text {trig }}=c / p\right)$. Consequently, the gains from the cooperative solution relatively to the non-cooperative solution become smaller and for low discount values the cooperative and non-cooperative solutions coalesce.

Following this rationale, one can find the critical value of the discount factor $\delta$ to sustain the cooperative solution. The critical value of the discount factor $(\delta)$ is higher when the threshold $B_{\text {lim }}$ is introduced (Equation 7, see supplementary materials Appendix G) therefore the incentives to deviate from the cooperative solution is higher leading to our first hypothesis:

Hypothesis 1: We expect less cooperation when a tipping point is introduced (T1 and T2).

We analyze the level of cooperation through the stock size left after exploitation. A stock size below the optimal level $\left(B_{\text {opt }}\right)$ indicates an over-exploitation driven by non-cooperative behaviors. We also introduce a proxy of non-cooperative behaviors, the ratio between the harvest decision $\left(y_{i, t}\right)$ and the myopic harvest strategy $y^{e}(B)$ determined as a function of the stock size 366 (see supplementary material Appendix $\mathrm{H}$ for a description of the myopic harvest strategy $y^{e}(B)$ ). 367 A value equal to 1 indicates that the participant chose to play as a selfish harvester maximizing her/his current payoff ${ }^{8}$, whereas a value inferior to 1 indicates that the participant intended to cooperate.

Now turn to the case where the position of the threshold is uncertain. Considering riskneutral players, the problem facing by each subject is now: 


$$
\pi_{i, t}=\left\{\begin{array}{l}
p y_{i, t}-C\left(B_{t}\right) \frac{y_{i, t}}{Y_{t}}, \text { for } B_{t}>B_{\lim }^{\max } \\
p y_{i, t}-C\left(B_{t}\right) \frac{y_{i, t}}{Y_{t}}-\alpha \cdot\left[1-\left(\frac{B_{t}-B_{\text {Iim }}^{\min }}{B_{\lim }^{\max }-B_{\lim }^{\min }}\right)\right], \text { for } B_{t} \in\left[B_{\lim }^{\min } B_{\lim }^{\max }\right] \\
p y_{i, t}-C\left(B_{t}\right) \frac{y_{i, t}}{Y_{t}}-\alpha, \text { for } B_{t}<B_{\lim }^{\min }
\end{array}\right.
$$

In front of ambiguous situation, the size of the stock resulting from non-cooperative strategy (where further depletion becomes unprofitable) becomes superior to $B_{\text {lim }}$ when an uncertain tipping point is introduced (T2). Following the same rationale as for defining hypothesis 1 , the gains from the cooperative solution relatively to the non-cooperative solution become smaller and lead to our second hypothesis:

Hypothesis 2: We expect less cooperation in T2 than in the known threshold position treatment T1.

\subsection{Statistical Analysis}

We first compare means and proportions across the treatments of main variables (Table 3). We used respectively the non-parametric Kruskal-Wallis and a Pearson's chi square tests for comparisons of means and proportions (Table 4). All reported p-values are two-sided and we only consider the first 15 rounds of the game for our analysis.

\section{Table 4 around here}

Then we analyze pledges and players' beliefs by classifying subjects according to their ability during the experiment to predict other player's behavior (belief elicitation) and their intentions to follow or not the pre-agreements during the game (i.e. pledges before harvest decisions). We define 3 types of subjects based on their mean prediction, beliefs errors: optimistic (belief $<$ others harvest), realistic (belief $=$ others harvest) and pessimistic (belief $>$ others harvest). We also define 3 types of subject's behavior according to their mean responses (harvest decisions) to others' pledge: altruistic (harvest decision < pledges/ $(\mathrm{N}-1)$ ), consensual (harvest decision $=$ pledges $/(\mathrm{N}-1)$ ) and free-rider (harvest decision $>$ pledges $/(\mathrm{N}-1)$ ). The subject type (Table 3) is a classification of subjects based on their highest frequency belief errors (optimistic, realistic or pessimistic) and intended harvest behaviors (free-rider, consensual or altruistic).

Finally, the experimental data, are analyzed with a population average generalized estimating equation model (GEE, developed by Zeger \& Liang 1986) with the "geepack" library (Halekoh et al., 2006) available in the programming language R (Team R Core 2016). The GEE model approach is an extension of the Generalized Linear Model (GLM). It provides a semi-parametric approach to longitudinal data analysis. Longitudinal data refers to non-independent variables derived from 
repeated measurements. We measure repeated decisions of participants which are correlated from one period to another. The GEE model allows an analysis of the average response of a group, i.e. the average probability of making a myopic harvest decision given the changes in experimental conditions, accounting for within-player non-independence of observations. The decision of a participant in year $t+1$ is linked to his decision in year $t$, thus violating the hypothesis of independence of the observations formulated in the classical regression methods. For controlling group dependences which occur through resource stock and social effects, we performed the same GEE analysis on the average group ratio of harvest decisions over myopic strategies. In this model, we consider that a correlation of the mean group in period $t+1$ is linked to the decisions in period t.

The modeling approach also requires a correlation structure, although this methodology is robust to a poor specification of the correlation structure (Diggle et al. 2002). Our dataset consists of a series of successive catch decisions made by a participant during each phase. The grouping variable of the observations is therefore based on each experiment. Since the data is temporally organized, a self-regressive correlation structure (AR-1) is selected. Model selection is performed by testing combinations of the covariables (R package MuMIn, Barton 2014) based on Pan's quasi-likelihood information criterion (QIC, Pan 2001) and individual Wald test.

We focus our analysis on the ratio of the harvest decision and the myopic harvest strategy. This variable, which is a proportion that can be modeled by a binomial distribution with a logit link function, specifying a variance of the form: $\operatorname{var}\left(Y_{i, t}\right)=p_{i, t .}\left(1-p_{i, t}\right)$, with $Y_{i, t=} \frac{y_{i, t}}{y^{e}(B)}$ corresponding to the response variable for participant $i$ during period $t$ and $p_{i, t}$ the probability of the expected value of $Y_{i, t}\left(E\left[Y_{i, t}\right]=p_{i, t}\right)$. As for the logistic regressions, we tested for specification errors, goodness-offit, multicollinearity as well as for influential observations.

\section{Results}

\subsection{Overall exploitation management decision patterns}

We found significant differences between treatments (Table 4). First, the threshold treatment groups (T1, T2) cooperated more on average, participants used significantly less myopic strategies and groups depleted significantly less the resource (higher average stocks). The groups playing in the T1-T2 treatments which exceeded the threshold, experienced an important cost that reduced drastically their profit. We therefore observed a lower average profit with a higher variability between groups. Furthermore, we observed an effect of uncertainty around the threshold (T2). Groups who experienced threshold uncertainty cooperated more if we consider 
the mean ratio of harvest decision on the myopic strategy and the mean resource level. However, the proportion of groups exceeding the threshold was higher than in the first treatment (T1) ${ }^{9}$ The overall catch decreasing pattern until the steady state stock size corresponding to the trigger strategy was found similar between groups in the treatment without a threshold (T0, Figure 3). All groups in the treatment T0 followed the trigger strategy and exploited the resource until the non-cooperative equilibrium ( $B_{\text {trig }}$ of 10 units). Only in 3 experiments over 34 , the biomass level was managed close to its long-term optimal level (40 units), for which the regeneration rate was the highest and the harvesting cost was low. They all belong to the treatments groups (one in T1 and two in T2).

In contrast with our theoretical prediction, the majority of groups (7) in the certain thresholds treatments (T1) harvested beyond the threshold. None of these groups was able to reverse the negative trend of stock depletion despite the high penalty cost. We observed the same pattern in the uncertain threshold treatment (T2) with 7 cases of exploitation falling beyond the threshold level. Moreover, despite the high cost related to the full depletion of stocks, two groups have intentionally exhausted the resource to end the experiment.

Figure 3 around here

We observed a lower proportion of myopic strategies in the threshold treatments (T1 and T2) which contradict the theoretical predictions (Figure 4). Moreover, we noticed more cooperation (i.e. a lower proportion of myopic strategies) in the uncertain threshold treatment than under other experimental conditions (Table 3). We also clearly discern a time pattern linked with the scarcity of the resource regardless of the treatment.

Figure 4 around here

To go further into the analysis of individual strategies, we observed that the high mean harvest level (Myopic behavior, Figure 5) in T0 during the first rounds ( 0 to 8 ) led the stock to $B_{\text {trig }}(10$ units) and decreased profits to zero as a result of the application of the trigger strategy. Participants' announcements (pledges) and harvest decisions were helpful to understand the start of the trigger strategy (punishment of free-riders by overexploiting the stock until further depletion becomes unprofitable). During the first rounds in which we observed the highest mean harvest decision, participant's pledges were strictly inferior to harvests driving participants into intended free-riding behavior (intended behavior $>0$ ). On the other hand, mean participants' beliefs were too optimistic: they expected other players to harvest less than their announcements (belief error $<0$ ). Threshold treatments exhibited the same pattern with a less marked trend in 
473

474

475

476

477

478

479

480

481

482

483

484

485

486

487

488

489

490

491

492

493

494

495

496

497

498

499

500

501

502

503

504

505

506

free-riding intended behaviors and prediction of other participants' harvests. The classification into distinct subject types summarizes this information by showing the highest proportion of freeriders and optimistic participants in the experiments (Figure 6). Likewise, this information highlights the high frequency of consensual participants which strengthens the theoretical hypothesis that participants use consensual punishment strategy.

Figure 5 and Figure 6 around here

\subsection{Exploring predictors for cooperation}

The selected GEE regression model (Table 5) ${ }^{10}$ reveals that groups playing the threshold treatment (T1 and T2, p < 0.001) are deemed more cooperative. On average, the odds, ceteris paribus, of behaving myopically in the no threshold treatment (T0) over the odds of behaving myopically in the threshold treatments (T1 or T2) is about 2.56 (inverse of the odds in Table 5). In terms of percentage of variation, the odds of behaving myopically among the no threshold treatment groups is around $156 \%$ higher than groups in the threshold treatment. The threat to trespass the threshold enhances cooperation by mitigating selfish behaviors.

Table 5 around here

We can also identify the effect of the resource scarcity on subjects mean harvest decisions. When subjects start experiencing scarcity, they significantly tend to select myopic decisions (biomass level effect, $\mathrm{p}<0.001$ ). Participants are stuck in short-sighted competitive behaviors. In all treatments, the proportion of myopic decisions increases by approximately a factor 3 to 4 between the first and the last rounds of the experiment (Figure 4). This observation is confirmed by the average continuous decreasing trend of biomass throughout time (Figure 3).

The subject type is also an important explanatory variable which is defined by the ability of participants during the experiment to predict other players' behaviors (belief error) and their intentions to follow or not the agreement contracted during the game (intended behavior, Table 3). The presence of free-riding participants significantly affects the mean odds of choosing myopic strategies. Those participants who deliberately deviated from the other pledges (catch > pledge/2) selected on average more myopic strategies than other players and led to stock depletion with the implementation of the punishment (trigger) strategy. Furthermore, the significant positive coefficient of realistic and consensual participants confirms our previous analysis that participants use consensually a punishment strategy. 


\section{Discussion and Conclusion}

508 This article studies the effects of an endogenously driven catastrophic change in the economic conditions, on the management of a CPR, the EABFT international fishery. We showed empirically that the threat of economic sanctions significantly increases the likelihood of observing coordinated actions and decreases free-riding behaviors. International fishery agreements are rarely self-enforcing, and competition between states often results in stock overexploitation and rent dissipation (Munro 2007). Our experiment which reproduces a stylized representation of the decision-making process of ICCAT suggests, that States facing an endogenously driven catastrophic change would propose a collective target, in terms of total allowable catch, to avoid an economic collapse. This situation is close to the context of the threat of foreign trade ban which was envisaged in 2009, thus jeopardizing the future of the EABFT fishery, and has finally resulted in a coordinated decrease of quotas decided by the fishing countries.

Scientists have endeavored to support RFMO management by identifying key target and limit reference points such as the Maximum Sustainable Yield (MSY) or the biomass limit to guide the collective management decisions of states involved in international fisheries (Caddy \& Mahon 1995, FAO 1995, de Bruyn et al. 2013), which are inherently uncertain (Francis \& Shotton 1997). Our research suggests that introducing economic sanctions such as trade restrictions associated with biological limit reference points and their uncertainties would discipline free-riding behaviors and foster the emergence of self-enforcing agreements.

The influence of a tipping point on resource exploitation observed in this study strengthens previous observations by Schill et al. (2015) and Lindahl et al. (2016). In such a dynamic CPR experiment designs, which introduced the resource dynamics, the focal point represented by the cooperative solution changes over time and is path-dependent. The incentive to deviate from a past agreement increases over time as the probability of a game continuation decreases. Such conditions make cooperation and coordination more unlikely. This has been 532 demonstrated experimentally by Mason \& Phillips (1997) when comparing static and dynamic 533 designs. In our experiment, which is set as a non-cooperative game allowing communication only 534 through a non-binding pledge process, the introduction of a tipping point drastically changes the 535 outcomes from systematic overexploitation following the use of a trigger strategy toward 536 cooperative outcomes with a self-enforcing agreement. Nonetheless, whereas uncertainty around 537 the existence or the location of tipping point fosters cooperation in CPR dilemma (Polasky et al. 538 2011, Schill et al. 2015), it impedes the collective contribution in a public good game (Barrett \& 539 Dannenberg 2012, 2014). The implications of potential regime shifts also depend on whether the 540 shift is triggered by an individual's decision or whether it would happen due to external forces 541 (exogenous). In the latter case, if an individuals' decisions have no impact on the likelihood of a 
542 catastrophic event, they will secure their earnings by harvesting more aggressively (Polasky et al. 543 2011).

544 In contradiction to our theoretical expectations, the introduction of a tipping point and 545 addition of uncertainty around the quantification of the tipping point influenced exploitation 546 strategies by enhancing instead of decreasing cooperation. Deviations from predictions in 547 uncertain decision problems are well known. From empirical evidence, we know that in complex 548 and uncertain decision problems (as used in our experiment), the assumptions underpinning the 549 expected utility theory are questionable (e.g., Tversky and Kahneman 1974). Individuals typically 550 deviate from expected utility maximization and rely instead on heuristics (Moxnes 1998, Hey et 551 al. 2009). Deviations from theoretical predictions have also been observed when a group 552 managing a CPR faces different probability levels regarding the existence of a tipping point (Schill 553 et al. 2015).

554 In this study, we found a clear trend of non-cooperative (myopic) strategies over time 555 regardless of the treatment which could be correlated to the scarcity of the resource. Subjects are 556 prone to competitive and more intensive fishing behavior when the resource becomes scarcer. 557 More surprisingly, the higher cost of exceeding the threshold does not affect this pattern. This 558 result confirms previous findings by Osés-Eraso et al. (2008). They have observed that users 559 responded to scarcity with caution by observing harvest levels directly but were nevertheless not 560 able to avoid resource extinction. If we directly observed the harvest instead of the ratio between 561 harvest and the myopic harvest level, subjects would have decreased their catch levels. However, 562 the latter does not represent a good indicator of the cooperation level. When the situation 563 becomes more competitive with fewer natural resources to share, participants' behaviors seem to 564 be driven by myopic strategies.

565 Although the introduction of an endogenous tipping point improved group coordination, 566 very few groups (3 cases over 34 ) were able to maintain the biomass level close to the long-term 567 optimal level (40 units) in our experiment. The complexity and the highly competitive feature of 568 the experiment do not allow an agreement to emerge efficiently with only the threat of using a 569 trigger strategy. Communication that has been reduced to pledges in this experiment is a key 570 factor in achieving agreement to cooperate in CPR settings (Ostrom 2006). Face-to-face 571 communication has been identified as the trigger for group agreement in dynamic CPR 572 experiments (Schill et al. 2015, Lindahl et al. 2016). Nonetheless, we have left the study of 573 cooperative management of CPRs involving communication for future work. Previous theoretical 574 works based on game theory have focused on the formation of international fisheries agreements 575 through coalition games, showing how the benefits of cooperation are allocated to each State 576 involved in the coalition (Pintassilgo et al. 2015). Only a few experimental works have undertaken 
the study of formal sharing institutionally agreements such as voting to gain agreement in large CPR settings (Walker et al. 2000, Margreiter et al. 2005).

It is worthwhile noting that our results stem from laboratory experiments with students as subjects. The results would require external validation in the real context of regional fishery management organizations, and a next step would be for example to replicate this experience at the ICCAT Commission with actual decisioners. Furthermore, several dimensions other than the payoff derived from harvesting fish could be added individuals' objectives. States are willing to maximize yield and employment or to include non-market values. Overlooking all the variety of objectives could have been one of the reasons for the failures of sustainable fisheries management (Hilborn, 2007). Few studies have analyzed the role of different payoffs on cooperation (e.g. Pintassilgo et al. 2018, Mullon \& Mullon 2018). However, merely accounting for new dimensions in the objectives of the states involved in international fisheries is not sufficient to overcome the trap of non-cooperation (Pintassilgo et al. 2018). Increasing the group size and integrating asymmetry between individuals may also have been a factor inhibiting the ability of groups to coordinate even in the presence of an endogenous tipping point. While group size has been identified as a critical factor affecting the success of cooperation in international fisheries, asymmetry between individuals has no clear effect on cooperation depending on the setting and the definition of asymmetry, which can be related to unequal interests, objectives, costs or information (Hannesson 2011, Pintassilgo 2015).

\section{Acknowledgments}

We are thankful for valuable comments received from Marc Willinger, Stefano Farolfi, Dimitri Dubois, Nils Ferrand, Sander De Waard, members of the Laboratoire d'Economie Expérimentale de Montpellier (LEEM) working group and members of the IM2E Experiments on Uncertainty and Social Relations workshop. We thank Julien Lebranchu for his computer support, Dimitri Dubois for his experiment assistance and Anne-Catherine Gandrillon for her language corrections. We are also thankful for valuable comments received from two anonymous reviewers. P. Guillotreau and T. Vallée acknowledge the financial support of the French research ANR program CIGOEF (ANR17-CE32-0008) and DOCKSIDE project, co-funded by the Erasmus Plus Programme of the European Union. Finally, we acknowledge the University of Nantes and IFREMER for the funding of a PhD. Last but not least, we would like to thank our experiment participants. 


\section{Notes}

613

614

615

616

617

618

619

620

621

622

623

624

625

626

627

628

629

630

631

632

633

634

635

636

637

638

639

640

641

642

643

644

645

1. The experimental design we use in this paper can be regarded as providing a limiting case where transaction costs linking to communication are prohibitively costly rendering the difficulties to reach an agreement within Regional Fisheries Management Organisation (RFMO) such as ICCAT.

2. As in Lindahl et al. (2016), to ensure an unknown time horizon, we varied the end-time between and within groups.

3. This cost function implicitly assumes that the cost per unit of fishing effort is constant and the catch per unit of effort is proportional to the size of the exploited stock.

4. A $40 \%$ uniform uncertainty range was selected to represent a high uncertainty level around the position of Blim.

5. Punishment strategies may last a finite number of periods. As we are interested in the effects of increasing the fishing through the introduction of a tipping point we keep simple strategies.

6. A more general way to describe the conditions for cooperation can be defined following the logic of Mason \& Phillips (1997). Consider a cooperative harvest function, $y_{\text {coop }}\left(B_{t}\right)$, a trigger strategy can be described by playing cooperatively $y_{\text {coop }}\left(B_{t}\right)$, as long as no one has defected. If one of the participants deviates from the optimal solution, then others will punish him by fishing down the stock with harvest $y_{\text {dev }}\left(B_{t}\right)$, afterwards and forever. Using the cooperative harvest and resulting stock path, we may derive the net present value for the player under cooperation $N P V_{\text {coop }}\left(B_{t}\right)$. Similarly, we may calculate the noncooperative value function, $N P V_{\text {dev }}\left(B_{t}\right)$. The trigger strategy forms a subgame perfect equilibrium if the defection is not profitable, irrespective of the current state.

$$
N P V_{\text {coop }}\left(B_{t}\right)>\pi_{\text {dev }}\left(y_{\text {dev }}\left(B_{t}\right)\right)+\delta N P V_{\text {dev }}\left(B_{t}\right)
$$

7. Myopic behavior constitutes a focal point distinguishable as the symmetric harvest decision which maximises the current payoff (diagonal in the payoff table in the supplementary material Appendix D).

8. We also test the potential effect of playing 2 games (phases) sequentially. We did not find any significant difference between phases using the Mann-Whitney-Wilcoxon test on group averages (supplementary material Appendix I).

9. We also compared GEE models to random group effect generalised linear models (GLMM with package 'Ime4' Bates et al., 2015 in R, supplementary material Appendix J). The results are qualitatively similar with a higher magnitude of treatment and free-rider participant coefficients. 


\section{References}

647 Bailey, M., Sumaila, R. U., and Lindroos, M. 2010. Application of game theory to fisheries over three 648 decades. Fisheries Research, 102(1), 1-8.

649 Barrett, S. and Dannenberg, A. 2012. Climate negotiations under scientific uncertainty. 650 Proceedings of the National Academy of Sciences, 109(43), 17372-17376.

651 Barrett, S. and Dannenberg, A. 2014. Sensitivity of collective action to uncertainty about climate 652 tipping points. Nature Climate Change, 4(1), 36-39.

653 Barton, K. (2014). Package 'MuMIn': multi-model inference. R package. Version 1.9. 13.

654 Bates D., Maechler M., Bolker, B., and Walker, S. 2015. Fitting Linear Mixed-Effects Models Using 655 Ime4. Journal of Statistical Software, 67(1), 1-48

656 Biggs, R., Blenckner, T., Folke, C., Gordon, L., Norstrom, A., Nystrom, M. and Peterson, G. 2012. 657 Regime shifts. In: Hastings, Gross L. (eds) Sourcebook in theoretical ecology. University of 658 California Press, Berkeley.

659 Botelho, A., Dinar, A., Costa Pinto, L. M. and Rapoport, A. 2014. Time and uncertainty in resource 660 dilemmas: equilibrium solutions and experimental results. Experimental Economics, 17(4), 649661672.

662 Brasão A., Duarte C. C. and Cunha-E-Sá M. A. 2000. Managing the Northern Atlantic Bluefin Tuna 663 fisheries: the stability of the UN fish stock agreement solution. Marine Resource Economy, 15, 341664360.

665 Budescu, D. V., Rapoport, A. and Suleiman R. 1995. Common-pool Resource Dilemmas under 666 Uncertainty: Qualitative Tests of Equilibrium Solutions, Games and Economic Behavior, 10(1), 667 171-201.

668 Caddy, J. F. and Mahon, R. 1995. Reference points for fisheries management, FAO Fisheries 669 Technical Paper, 347, Rome, Italy, p.83.

670 Castillo, D., Bousquet, F., Janssen, M. A., Worrapimphong, K. and Cardenas, J. C. 2011. Context 671 matters to explain field experiments: results from Colombian and Thai fishing villages. Ecological 672 Economics, 70, 1609-1620.

673 Cardenas, J. C. 2009. Experiments in environment and development. Annual Review of Resource 674 Economics 1, 157-182.

675 Cardenas, J. C., Janssen, M., Bousquet, F. 2013. Dynamics of rules and resources: three new field 676 experiments on water, forests and fisheries. In: List, J. A., Price, M. K. (eds) Handbook on 677 experimental economics and the environment. Edward Elgar Publishing, Cheltenham.

678 Chaudhuri, A. 2011. Sustaining cooperation in laboratory public goods experiments: A selective 679 survey of the literature. Experimental Economics, 14, 47-83. 
680 Chen, D. L., Schonger, M., and Wickens, C. 2016. oTree - An open-source platform for laboratory, 681 online, and field experiments. Journal of Behavioral and Experimental Finance, 9, 88-97.

682 Clark C. W. 1980. Restricted access to common-property fishery resources: a game-theoretic 683 analysis. In Dynamic Optimization and Mathematical Economics, Liu, P. T. (eds), 117-32. New 684 York: Plenum.

685 Cullis-Suzuki, S. and Pauly, D. 2010. Failing the high seas: A global evaluation of regional fisheries 686 management organizations. Marine Policy, 34, 1036-1042.

687 De Bruyn, P., Murua, H. and Aranda, M. 2013. The Precautionary approach to fisheries 688 management: How this is taken into account by Tuna regional fisheries management 689 organisations (RFMOs). Marine Policy, 38, 397-406.

690 Diggle, P. J., Heagerty, P., Liang, K. Y. and Zeger, S. L. 2002. Analysis of Longitudinal Data (second 691 edition). Oxford: Oxford University Press.

692 Emery, T. J., Tisdell, J., Green, B. S., Hartmann, K., Gardner C., and León, R. 2015a. Experimental 693 analysis of the use of fishery closures and cooperatives to reduce economic rent dissipation 694 caused by assignment problems. ICES Journal of Marine Science, 72(9), 2650-2662.

695 Emery, T. J., Tisdell, J., Green, B. S., Hartmann, K., Gardner, C. and León, R. 2015b. An experimental 696 analysis of assignment problems and economic rent dissipation in quota managed fisheries. Ocean 697 \& Coastal Management, 106, 10-28.

698 FAO, 1995. Precautionary approach to capture fisheries and species introductions. Elaborated by 699 the Technical consultation on the precautionary approach to capture fisheries (Including Species 700 Introductions). FAO Technical Guidelines for Responsible Fisheries vol. 2, 6-13, Lysekil, Sweden.

701 Fischer, M. E., Irlenbusch, B. and Sadrieh, A. (2004). An intergenerational common-pool resource 702 experiment. Journal of Environmental Economics and Management, 48(2), 811-836.

703 Folke, C., Carpenter, S., Walker, B., Scheffer, M., Elmquist, T., Gunderson, L. and Holling, C. 2004. 704 Regime shifts, resilience, and biodiversity in ecosystem management. Annual Review of Ecology, 705 Evolution and Systematics, 35, 557-581.

706 Francis, R. I. C. C. and Shotton, R. 1997. Risk in fisheries management: a review. Canadian Journal 707 of Fisheries and Aquatic Sciences, 54, 1699-1715.

708 Fromentin, J. M., Bonhommeau, S., Arrizabalaga, H. and Kell, L. T. 2014. The spectre of uncertainty 709 in management of exploited fish stocks: The illustrative case of Atlantic bluefin tuna. Marine 710 Policy, 47, 8-14.

711 Fudenberg, D. and Tirole J. 1998. Game Theory. MIT Press, Cambridge, MA, USA.

712 Fulton, E. A., Smith, A. D., Smith, D. C. and van Putten, I. E. 2011. Human behavior: the key source 713 of uncertainty in fisheries management. Fish and fisheries, 12(1), 2-17.

714 Gordon, H. S. 1954. The economic theory of a common-property resource: the fishery. Palgrave 715 Macmillan, England, 178-203. 
716 Halekoh, U., Højsgaard, S. and Yan, J. 2006. The R package geepack for generalized estimating 717 equations. Journal of Statistical Software, 15(2), 1-11.

718 Hannesson, R. 1997. Fishing as a Supergame. Journal of Environmental Economics and 719 Management, 32(3), 309-322.

720 Hannesson, R. 2011. Game Theory and Fisheries. Annual Review of Resource Economics, 3(1), 721 181-202.

722 Hardin, G. 1968. The tragedy of the commons. Science, 162(3859), 1243-1248.

723 Harrison, G. W. and List, J. A. 2004. Field experiments. Journal of Economic Literature, 42(4), 10097241055.

725 Herr, A., Gardner, R. and Walker, J. M. 1997. An experimental study of time-independent and time726 dependent externalities in the commons. Games and Economic Behavior, 19(1), 77-96.

727 Hey, J. D., Neugebauer, T. and Sadrieh, A. 2009. An Experimental Analysis of Optimal Renewable 728 Resource Management: The Fishery. Environmental and Resource Economics, 44(2), 263-285.

729 R. Hilborn, R. 2007. Defining success in fisheries and conflicts in objectives. Marine Policy, 31(2), $730 \quad 153-158$.

731 Hutchings, J. A. and Myers, R. A. 1994. What can be learned from the collapse of a renewable 732 resource? Atlantic cod, Gadus morhua, of Newfoundland and Labrador. Canadian Journal of 733 Fisheries and Aquatic Sciences, 51, 2126-2146.

734 ICCAT. 2012. Report of the 2012 Atlantic Bluefin Tuna Stock Assessment Session. Collective 735 Volumes of Scientific Papers, 69(1), 1-198.

736 Janssen, M. A. 2010. Introducing ecological dynamics into common-pool resource experiments. 737 Ecology and Society 15(2), 7.

738 Juan-Jorda, M. J., Mosqueira, I., Cooper, A. B., Freire, J. and Dulvy, N. K. 2011. Global population 739 trajectories of tunas and their relatives. Proceedings of the National Academy of Sciences, 108, $740 \quad 20650-20655$.

741 Levhari, D., and Mirman, L. J. 1980. The great fish war: an example using a dynamic Cournot-Nash 742 solution. The Bell Journal of Economics, 322-334.

743 Lindahl, T., Crépin, A. S. and Schill, C. 2016. Potential Disasters can Turn the Tragedy into Success. 744 Environmental and Resource Economics, 65(3), 657-676.

745 Maguire J. J., Sissenwine, M., Csirke, J. and Grainger, R. 2006. The state of world highly migratory, 746 straddling and other high seas fish stocks, and associated species. Fisheries Technical Papers, 495, 747 FAO, Rome.

748 Margreiter, M., Sutter, M. and Dittrich, D. 2005. Individual and collective choice and voting in 749 common-pool resource problem with heterogeneous actors. Environmental and Resource 750 Economics, 32(2), 241-271. 
751 Maskin E. and Tirole J. 2001. Markov perfect equilibrium: I. Obervable actions. Journal of 752 Economic Theory, 100, 191-219.

753 Mason, C. F. and Phillips, O. R. 1997. Mitigating the tragedy of the commons through cooperation: 754 an experimental evaluation. Journal of Environmental Economics and Management, 34(2), 148755172.

756 McCain, J. S. P., Cull, D. J., Schneider, D. C. and Lotze, H. K. 2015. Long-term shift in coastal fish 757 communities before and after the collapse of Atlantic cod (Gadus morhua). ICES Journal of Marine 758 Science, 73(5), 1415-1426.

759 McWhinnie, S. F. 2009. The tragedy of the commons in international fisheries: an empirical 760 investigation. Journal of Environmental Economics and Management, 57, 312-333.

761 Messick, D. M., Allison, S. T. and Samuelson, C. D. 1988. Framing and communication effects on 762 group members' responses to environmental and social uncertainty. Applied behavioral 763 economics, 2, 677-700.

764 Milinski, M., Sommerfeld, R. D., Krambeck, H. J., Reed, F. A. and Marotzke, J. 2008. The collective765 risk social dilemma and the prevention of simulated dangerous climate change. Proceedings of the 766 National Academy of Sciences, 105(7), 2291-2294.

767 Moreno-Sánchez, R. and Maldonado, J. H. 2010. Evaluating the role of co-management in 768 improving governance of marine protected areas: an experimental approach in the Colombian 769 Caribbean. Ecological Economics, 69, 2557-2567.

770 Moxnes, E. 1998. Not Only the Tragedy of the Commons: Misperceptions of Bioeconomics. 771 Management Science, 44(9), 1234-1248.

772 Mullon, C. and Mullon, C. 2018. A constraint-based framework to study competition and 773 cooperation in fishing. Fisheries Research, 203, 74-83.

774 Munro, G. 1979. The optimal management of transboundary renewable resources. Canadian 775 Journal of Economics, 12(3), 355-376.

776 Munro, G. 2007. Internationally Shared Fish Stocks, the High Seas, and Property Rights in 777 Fisheries. Marine Resource Economics, 22(4), 425-43.

778 Munro, G., Van Houtte, A. and Willmann, R. 2004. The Conservation and Management of Shared 779 Fish Stocks: Legal and Economic Aspects, FAO Fisheries Technical Paper No. 465, Rome.

780 Osés-Eraso, N., Udina, F. and Viladrich-Grau, M. 2008. Environmental versus Human-Induced 781 Scarcity in the Commons: Do They Trigger the Same Response? Environmental and Resource 782 Economics, 40(4), 529-550.

783 Ostrom, E. 2006. The value-added of laboratory experiments for the study of institutions and 784 common-pool resources. Journal of Economic Behavior and Organization, 61(2), 149-163.

785 Ostrom, E., R. Gardner, and Walker, J. 1994. Rules, games, and common-pool resources. University 786 of Michigan Press, Ann Arbor, Michigan, USA. 
Pan, W. 2001. Akaike's information criterion in generalized estimating equations. Biometrics, 57(1), 120-125.

Pauly, D., Christensen, V., Dalsgaard, J., Froese, R., and Torres, F. (1998). Fishing down marine food webs. Science, 279(5352), 860-863.

Pintassilgo, P., Kronbak, L. G. and Lindroos, M. 2015. International Fisheries Agreements: A Game Theoretical Approach. Environmental and Resource Economics, 62(4), 689-709.

Poteete, A. R., Janssen, M. A., and Ostrom, E. 2010. Working together: collective action, the commons, and multiple methods in practice. Princeton University Press.

Polasky, S., de Zeeuw, A. and Wagener, F. 2011. Optimal management with potential regime shifts. Journal of Environmental Economics and Management, 62(2), 229-240.

Rapoport, A., Budescu, D. V., Suleiman, R. and Weg, E. 1992. Social dilemmas with uniformly distributed resources. In Liebrand et al. (Eds.). Social dilemmas: theoretical issues and research findings, 43-57, Oxford: Pergamon Press.

Schaefer, M. B. 1954. Some aspects of the dynamics of populations important to the management of commercial marine fisheries. Bulletin of inter-American tropical Tuna Commission, 1(2) 26-56. Scheffer, M., Westley, F. and Brock, W. 2003. Slow Response of Societies to New Problems: Causes and Costs. Ecosystems, 6(5), 493-502.

Schill, C., Lindahl, T., and Crépin, A. S. 2015. Collective action and the risk of ecosystem regime shifts: insights from a laboratory experiment. Ecology and Society, 20(1), 48.

Sumaila U. R. 2013. Game theory and fisheries. Essays on the tragedy of free for all fishing, Routledge.

Teh, L. and Sumaila, U. 2015. Trends in global shared fisheries. Marine Ecology Progress Series, $530,243-254$.

Team, R. C. 2016. R: A language and environment for statistical computing. R Foundation for Statistical Computing, Vienna, Austria. 2015. URL http. www. R-project.org.

Tversky, A., and Kahneman, D. 1974. Judgment under uncertainty: heuristics and biases. Science, 185, 1124-1131.

Walker, J. M. and Gardner, R. 1992. Probabilistic destruction of common-pool resources: experimental evidence. The Economic Journal, 102(414), 1149-1161.

Walker, J. M., Gardner, R., Herr, A., and Ostrom, E. 2000. Collective choice in the commons: Experimental results on proposed allocation rules and votes. The Economic Journal, 110(460), 212-234.

White C., Costello C. 2014. Close the high seas to fishing? PLoS Biology 12(3), e1001826.

Worm, B., Hilborn, R., Baum, J. K., Branch, T. A., Collie, J. S., Costello, C., Fogarty, M. J., Fulton E. J., Jennings, S., Jensen, O. P., Lotze, H., Mace, P., McClanahan, T., Minto, C., Palumbi, S., Parma, A., Ricard, D., Rosenberg, A., Watson, R., and Zeller, D. 2009. Rebuilding Global Fisheries. Science, 325(5940), 578-585. 
824 Zeger, S. L., and Liang, K. Y. 1986. Longitudinal Data Analysis for Discrete and Continuous 825 Outcomes. Biometrics, 42(1), 121-130.

826 
828 9.1. Appendix A. Flowchart of the steps in the experimental design.

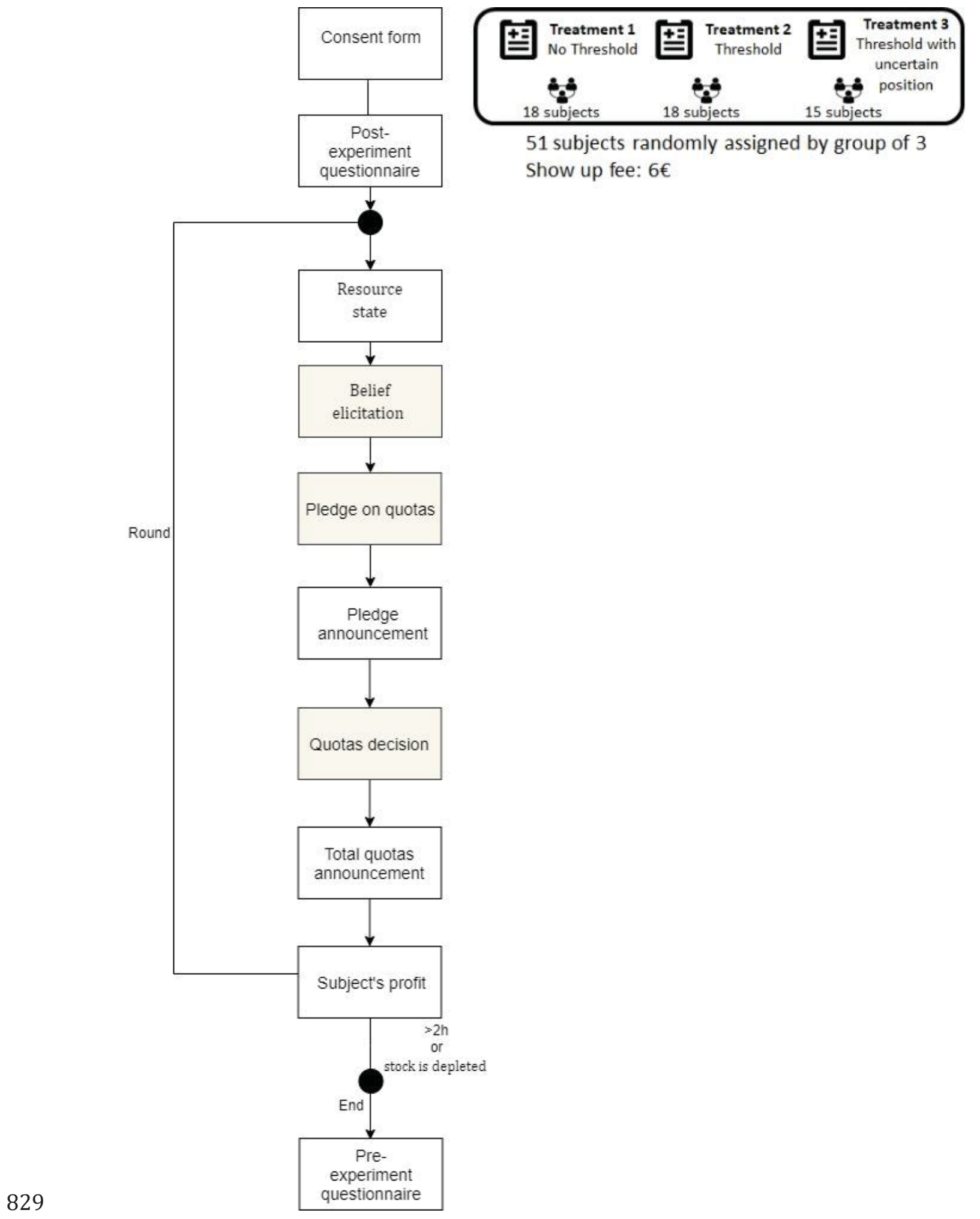




\section{Instructions treatment T0 (in quote additional instructions for T1 and T2)}

832 It is an experiment dealing with economic decision-making. We ask you to carefully read the 833 instructions. When all the participants have read these instructions an experimenter will proceed 834 to a re-reading aloud. We will then ask you to watch attentively a tutorial video to familiarise 835 yourself with the web interface of the experiment.

836 From now on, we ask you not to speak anymore. If you have a question raise your hand and an 837 experimenter will come to answer you privately. During the experiment, all your decisions will be treated anonymously. You will indicate your choices on the computer in front of which you are seated.

840

\section{General instructions}

842 This experiment has two parts. These instructions concern both parts 1 and 2 of the experiment.

843 One of these two parts will be chosen by drawing lot for your remuneration. Your earning at this 844 game will constitute your gain for the experience. It will be paid in cash at the end of the 845 experiment.

846 In this experiment, each of you is a policy maker of a country involved in the East Atlantic bluefin 847 tuna fishery. You and 2 other participants will form a group. You and your group members will 848 have a common access to the Atlantic bluefin tuna resource. Each of you, at each round (which 849 represents one year), will decide how many units (tons) of the resource you would like to harvest. 850 These catches will bring you earnings in units of profit (euros).

851 Before making your decision, you will have to 852 announce your catch to the other players, 853 without the latter engaging you in your 854 future private decision: you will be able to 855 follow it or not. At the same time, you will 856 also estimate the cumulated catches of the 857 other 2 members of your group. Finally, to 858 make your private catch decisions, you will 859 have access to catch proposals from other 860 members of your group as well as 861 information on the state of the resource from 862 the International Commission for the 863 Conservation of Atlantic Tunas (ICCAT).

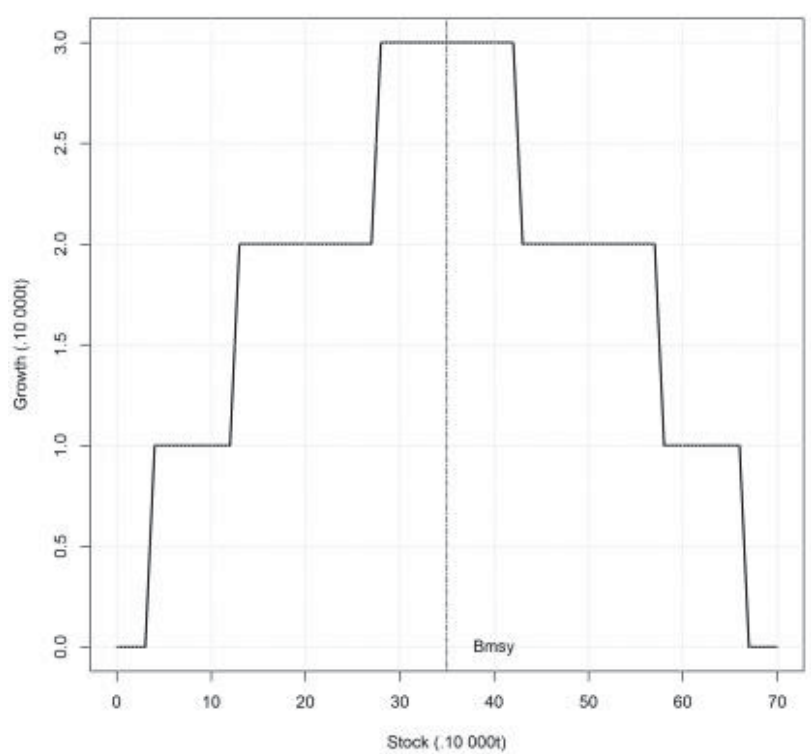

Figure 1 
864 Each part of the experiment lasts a certain number of rounds (years in the experiment), the 865 amount of rounds is unknown to you. The experiment also ends if the resource is depleted due to 866 excessive catches.

867

\section{Remuneration}

869 If you follow the instructions carefully and take sound decisions, you can earn money. One of the 870 games will be chosen by drawing lot for your remuneration. Your earning at this game will 871 constitute your gain for the experiment. Each profit you have accumulated by exploiting the 872 resource during each game separately will be converted into euros at a rate of 1 monetary units 873 of profit $=0.05 €$. You will begin each part of the experiment with 50 profit units, corresponding 874 to $2.50 €$. You will also be compensated for your exact expectations of the catch levels of the other 875 participants, $0.20 €$ for each exact expectation.

876

\section{Resource dynamic}

878 The bluefin tuna resource increases in each round depending on the size of the resource at the 879 beginning of the round, which in turn depends on the total harvest of the previous round (sum of 880 your and the other participant's harvest in the previous round).

881 The exact relation between the size of the resource stock and its regeneration is illustrated in 882 Figure 1. As the figure illustrates, if the total amount of catches exceeds the regeneration rate for 883 the round, the resource stock will decline. Contrariwise, if the total amount of catches is inferior 884 to the regeneration rate for the round, the resource stock will increase the next round. The 885 Maximum Sustainable Yield (MSY) indicated on the figure (from 28 to 42 resource units) is the 886 maximum amount of catch that allows the stock to remain constant from one round to the next.

887 For example if the resource stock is 50 units of the resource at the beginning of a round. If you, 888 harvest together with the 2 other members of your group 10 units in this round, the resource will 889 regenerate itself by 2 units and, hence, the resource stock will be $(50+2-10) 42$ units in the next 890 round.

891

892

Harvest choice

893 Each round, you will receive information about the resource stock size available and harvest 894 proposals from the 2 other members of your group. 
895

896

897

898

899

900

901

902

903

904

905

906

907

908

909

910

911

912

913

914

915

916

917

918

919

920

921

922

923

924

Based on this information, you will choose

how many units of resource you would like

to harvest with a choice between 0 to 5 units.

You, and the 2 other members of your group

could harvest each round a total of 15 units.

This amount of catch will bring you earning

which depends on your harvest level, but also on the harvest level of the 2 other participants and on the resource stock size.

The relation between your profit, the total amount of catch from your group and the resource stock size is illustrated in Figure 2. As illustrated in Figure 2, the most the

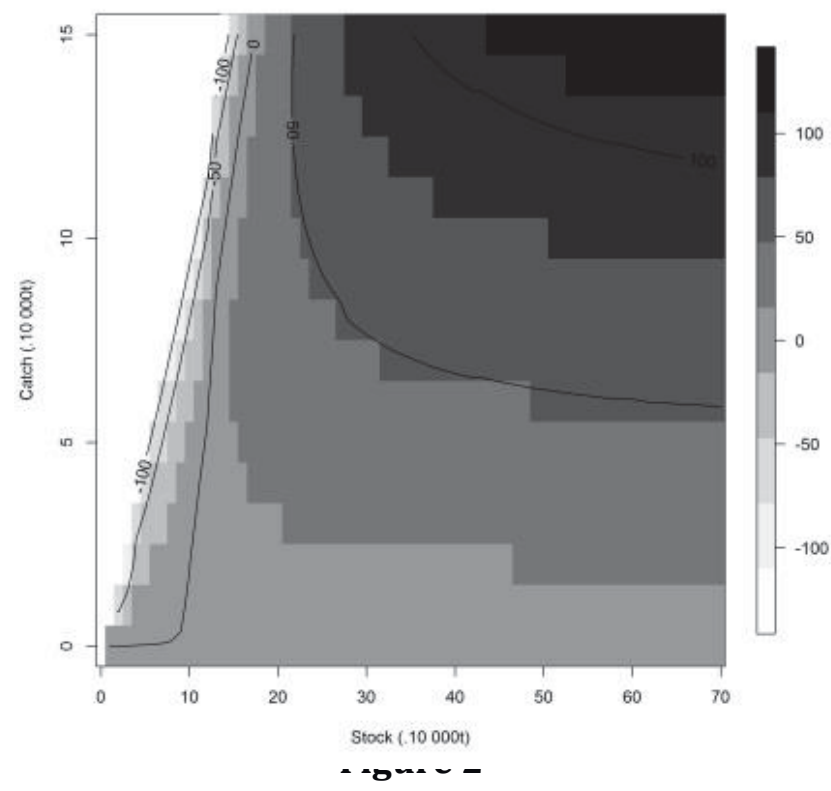
resource is depleted the less you could earn from harvest.

Your harvest decision is private but will be made public at the end of each round.

"Moreover, there is a threshold in the resource stock size at the level Blim of 20 resource units. If the level of the resource crosses this threshold, this will entail an additional cost of 30 profit units. This cost will greatly decrease your profit so as to make it negative whatever your decisions, even if you decide not to fish any more. You will therefore lose earnings as long as the resource is below the threshold Blim."1

"There is a threshold in the resource stock size at the level Blim. You do not know the exact position of this threshold, but only that it is in the range between 12 and 28 units of resource with the same probabilities. If the level of the resource crosses this threshold, this will entail an additional cost of 30 profit units. This cost will greatly decrease your profit so as to make it negative whatever your decisions, even if you decide not to fish any more. You will therefore lose earnings as long as the resource is below the threshold Blim."2

\section{Some rules}

- Talking is not permitted.

- You are not permitted to operate other software such as email or web pages during the experiment.

1 Additional instructions for T1

2 Additional instructions for T2 
- You may ask questions to the experimenter during the experiment if you have any 926 problems.

927 Before starting the experiment, you will be invited to follow a tutorial video presenting the web 928 interface of the experiment. Once this video has been watched, you can then complete the 929 identification form on the application page and fill in the comprehension test. Once the test has 930 been completed, you will have the opportunity to ask questions about the elements of the 931 experiment. Finally, at the end of the experiment, you will have to complete a short survey about 932 the experiment, and then you will have to wait until the experimenter calls you individually to 933 receive your payment. 


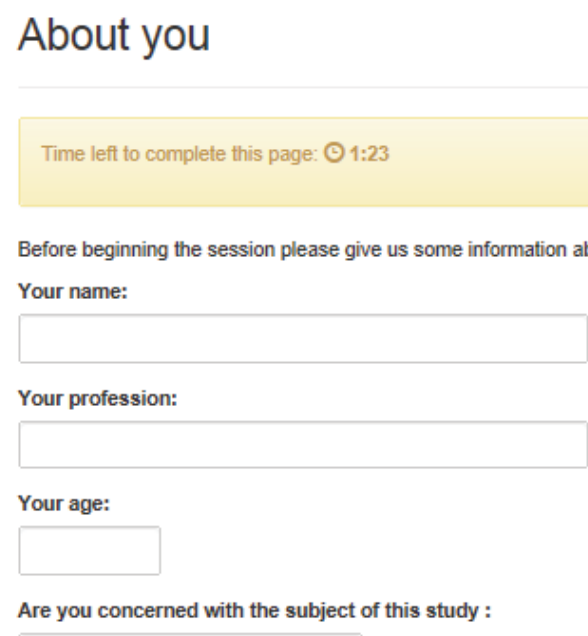

Are you concerned with the subject of this study :

Next

Test

Time left to complete this page: $\odot 4: 51$

Before beginning the session, We want to make sure that you understand the dynamic process which drive the resource level.

First of all, if at the beginning of the year the biomass is at a level of $2510^{4} \mathrm{t}$, could you indicate how many units (in $10^{4} \mathrm{t}$ ) the stock will grow for the next year? Use the growth function.

Resource growth in $10^{\wedge} 4 \mathrm{t}$ for the year:

(20.

Then, still with a stock of $2510^{4} \mathrm{t}$ if the 3 nations decide to harvest $910^{4} \mathrm{t}$, could you indicate how many profit (in $\left.10^{7} €\right)$ the harvest will generate this year? Use the profit function and round the value.

Total profit in $10^{\wedge} 7 €$ for the year:

(20.0.

Under the same conditions, if the 3 nations decide to harvest $910^{4} \mathrm{t}\left(3.010^{4} \mathrm{t}\right.$ each), Could you indicate how many profits in $10^{7} €$ you will win this year (individual profit)?

Use the table of individual profits.

Individual profit in $10^{\wedge} 7 €$ for the year:

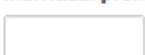




\section{Survey about the Experiment}

Time left to complete this page: (ㅇ:55

Please, complete this survey before proceeding to the payment.

Were you fully understand the dynamic of the resource? :

$\checkmark$

Has your group been able to cooperate?

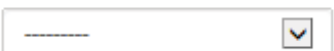

What was the main element responsible for cooperation or non-cooperation during the experiment?

$\checkmark$

Did the possible benefits in case of cooperation seem to you a necessary condition for cooperation during the expériment? :

$\checkmark$

Has uncertainty about the resource level in phase 2 impeded the development of a cooperative strategy? :

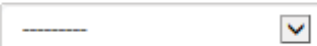

Has uncertainty about the level of the resource impeded your perception of your earnings and the dynamic of the resource? :

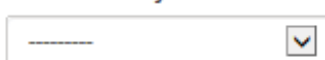

If you were not subject to the threshold limit, select: Not in my treatment.Else, has the uncertainty on the Blim threshold promoted your development of a cooperative strategy? :

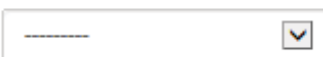

Next 

experiment for a resource size of 50 units. On the top the "Payoff table" and on the bottom the "Biomass variation table".

Individual profit

\begin{tabular}{|c|ccccccccccc|}
\hline \multirow{11}{*}{ My harvest } & \multicolumn{10}{c|}{ Sum of choices made by others } \\
\cline { 2 - 11 } & 0 & 1 & 2 & 3 & 4 & 5 & 6 & 7 & 8 & 9 & 10 \\
\hline 0 & 0.0 & 0.0 & 0.0 & 0.0 & 0.0 & 0.0 & 0.0 & 0.0 & 0.0 & 0.0 & 0.0 \\
\hline 1 & 8.1 & 8.0 & 8.0 & 8.0 & 8.0 & 8.0 & 7.9 & 7.9 & 7.9 & 7.9 & 7.8 \\
2 & 16.1 & 16.0 & 16.0 & 16.0 & 15.9 & 15.9 & 15.8 & 15.8 & 15.7 & 15.7 & 15.6 \\
3 & 24.1 & 24.0 & 23.9 & 23.9 & 23.8 & 23.7 & 23.7 & 23.6 & 23.5 & 23.4 & 23.4 \\
4 & 32.0 & 31.9 & 31.8 & 31.7 & 31.6 & 31.6 & 31.5 & 31.4 & 31.3 & 31.1 & 31.0 \\
5 & 39.9 & 39.8 & 39.7 & 39.6 & 39.4 & 39.3 & 39.2 & 39.1 & 38.9 & 38.8 & 38.7 \\
\hline
\end{tabular}

Biomass variation rate (\%)

\begin{tabular}{|c|cccccccccccc|}
\hline \multirow{3}{*}{ My harvest } & \multicolumn{1}{c|}{ Sum of choices made by others } \\
\cline { 2 - 9 } & 0 & 1 & 2 & 3 & 4 & 5 & 6 & 7 & 8 & 9 & 10 \\
\hline 0 & 4 & 2 & 0 & -2 & -4 & -6 & -8 & -10 & -12 & -14 & -16 \\
1 & 2 & 0 & -2 & -4 & -6 & -8 & -10 & -12 & -14 & -16 & -18 \\
2 & 0 & -2 & -4 & -6 & -8 & -10 & -12 & -14 & -16 & -18 & -20 \\
3 & -2 & -4 & -6 & -8 & -10 & -12 & -14 & -16 & -18 & -20 & -22 \\
4 & -4 & -6 & -8 & -10 & -12 & -14 & -16 & -18 & -20 & -22 & -24 \\
5 & -6 & -8 & -10 & -12 & -14 & -16 & -18 & -20 & -22 & -24 & -26 \\
\hline
\end{tabular}




\section{Results from harvest}

Time left to complete this page: $\bigcirc 0: 39$

You have selected an harvest of $0\left(10^{4} t\right)$. Your profit for the last year is $0.0\left(10^{7} \epsilon\right)$.

Your total profit since the beginning of the fishery is 0.0 (10? $\epsilon$ ).

This is equivalent to a real payment of $0.0 €$ Plus a bonus payment for your expectations of the level of exploitation of other nations of euros $0.20 €$. ICCAT commission gives you also the statistic from the total catch and profit realized last years.

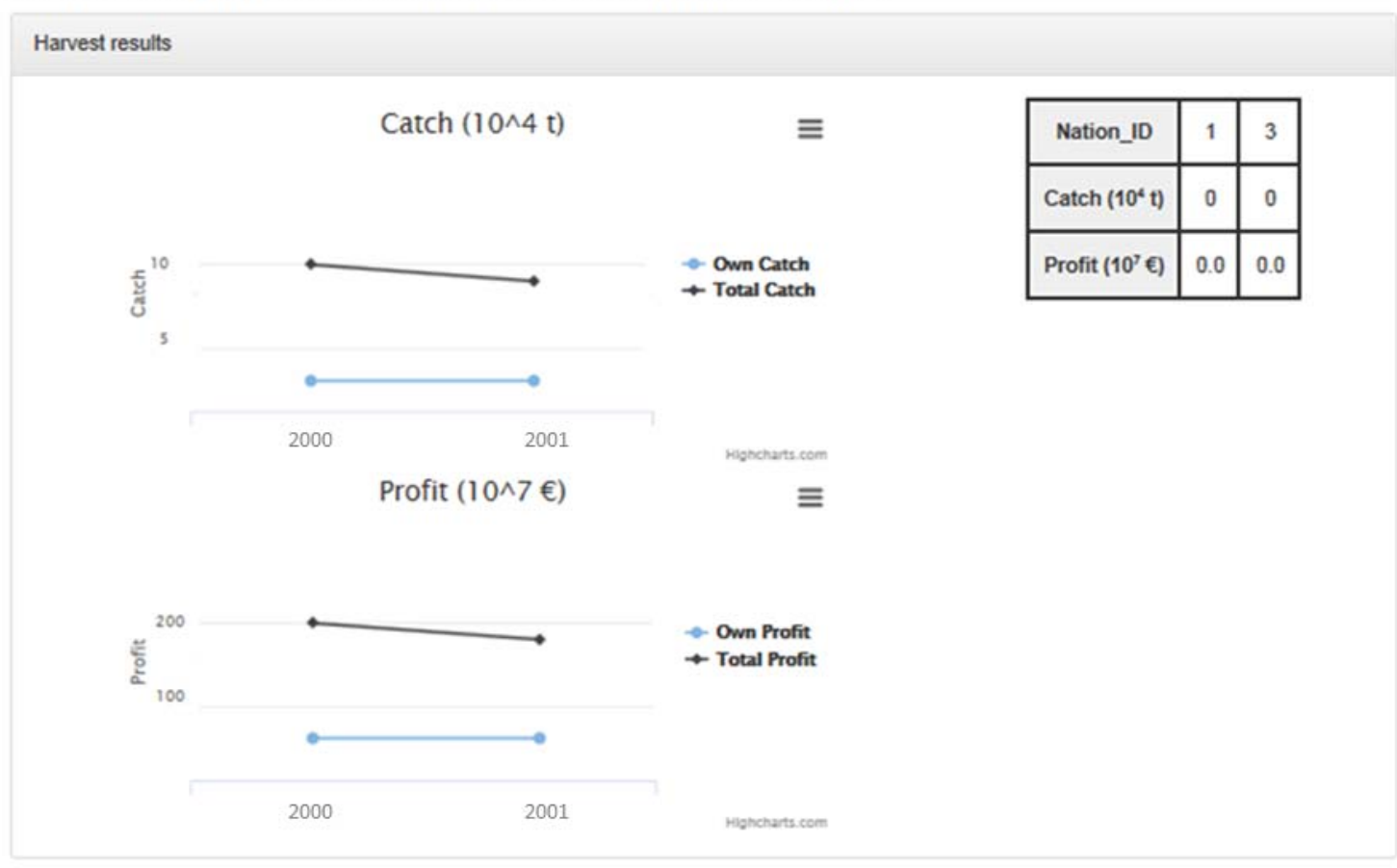

Scientific Assessment

The scientific body of ICCAT give you the projection of the biomass level under statu quo scenario:

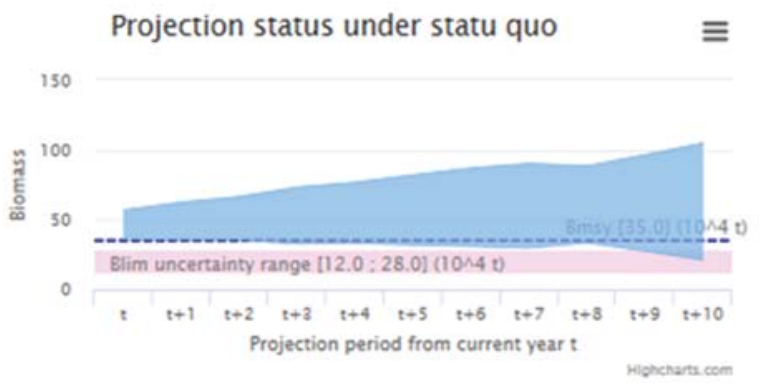


944 9.6.Appendix F. Relationship between the optimal stock level $\left(B_{\text {opt }}\right)$ and the 945 discount factor $(\delta)$.

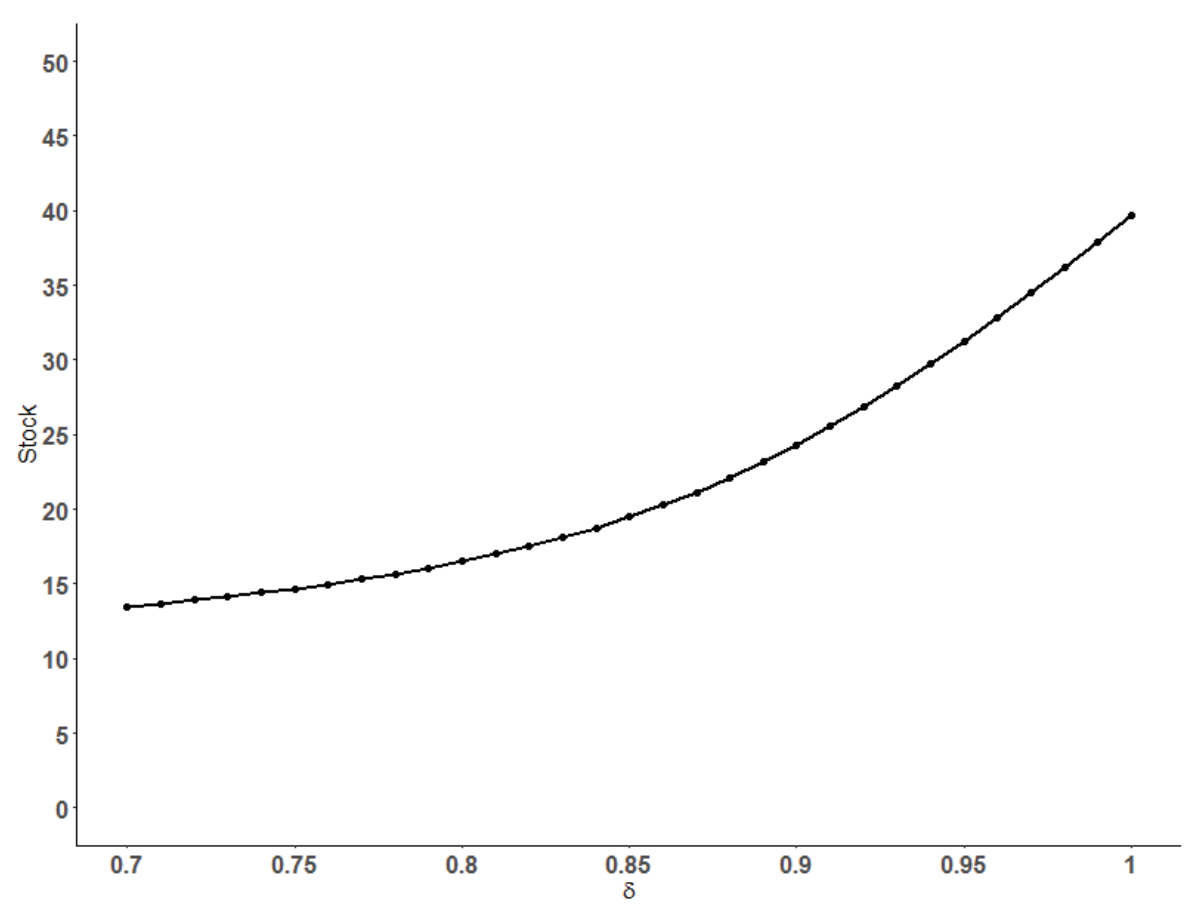

9.7. Appendix G. Relationship between the maximum number of players ( $N$ ) and the critical discount factor $(\hat{\delta})$ to sustain cooperative solution.

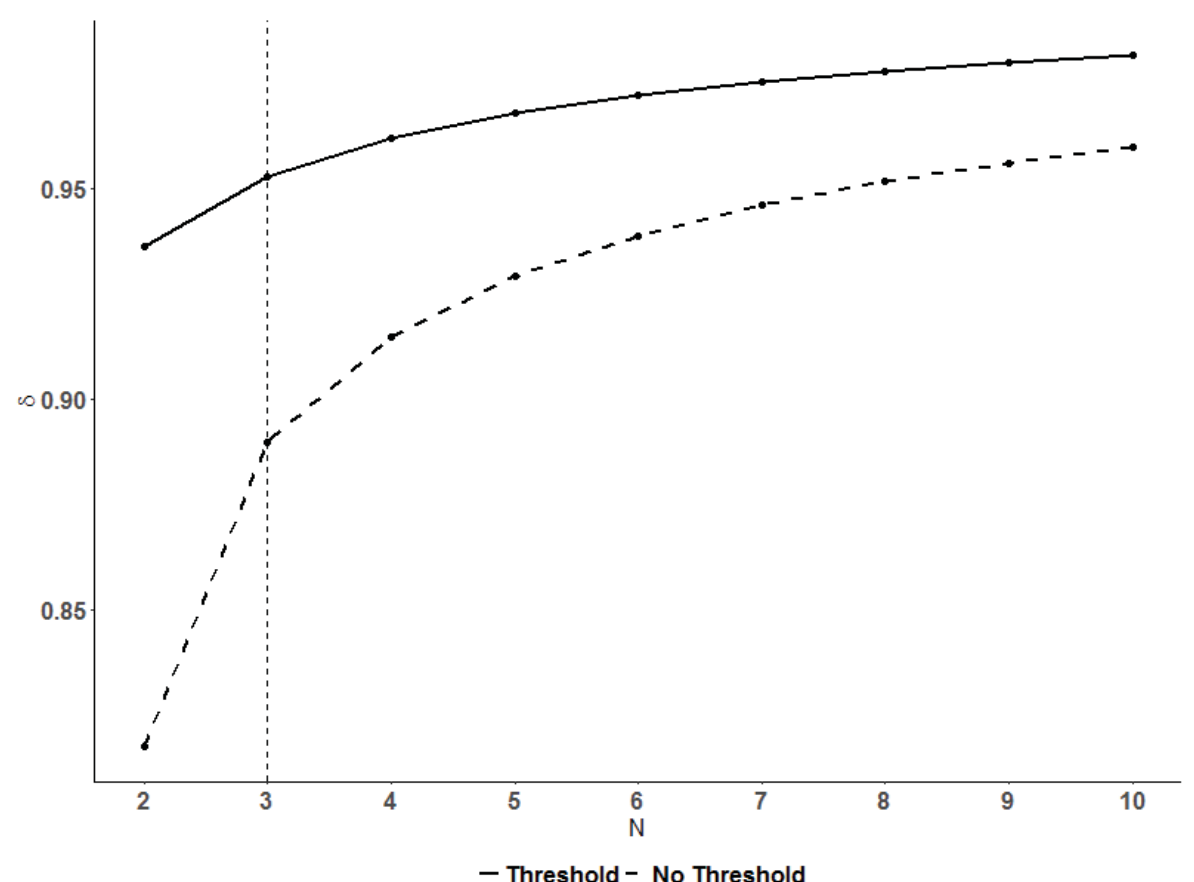


952 Considering that all participants have the same payoff function, we restrict the analysis to 953 symmetric outcomes in which each participant uses the same harvests strategy $y^{e}$ ). In this context 954 a participant $i$ seeks to maximise his profit flow by selecting a harvest strategy. Letting $\delta$ represent 955 the discount factor, common to all participants, the present discounted value of profit in period $t$, $956 V_{i, t}$ of each participant, satisfies the Bellman's recursion equation:

$$
V_{i, t}=\operatorname{Max}_{y_{i, t}}\left(\pi_{i, t}+\delta \cdot V_{i, t+1}\right)
$$

958

s.t $B_{t+1}=B_{t} \cdot\left[1+r \cdot\left(1-\frac{B_{t}}{K}\right)\right]-(N-1) \cdot y_{t}-y_{i, t}$

$$
y_{t}=y^{e}(B)
$$

960 Myopic behaviors result from neglecting the fact that current extraction decreases the future

961 value of the resource is defined by backward recursion of the Bellman equation H1 considering

962 the discount factor $\delta$ whichtends 0 . Therefore, we define the collective ( $N$ participants) myopic 963 path for each experimental treatment: without tipping point, when a tipping point is introduced 964 and when the position of the tipping point is uncertain (on the left, middle and on the right 965 respectively). We consider risk-neutral players when the position of the tipping point is uncertain.

966 The risk neutral players based their harvest strategy upon the following profit function:

967
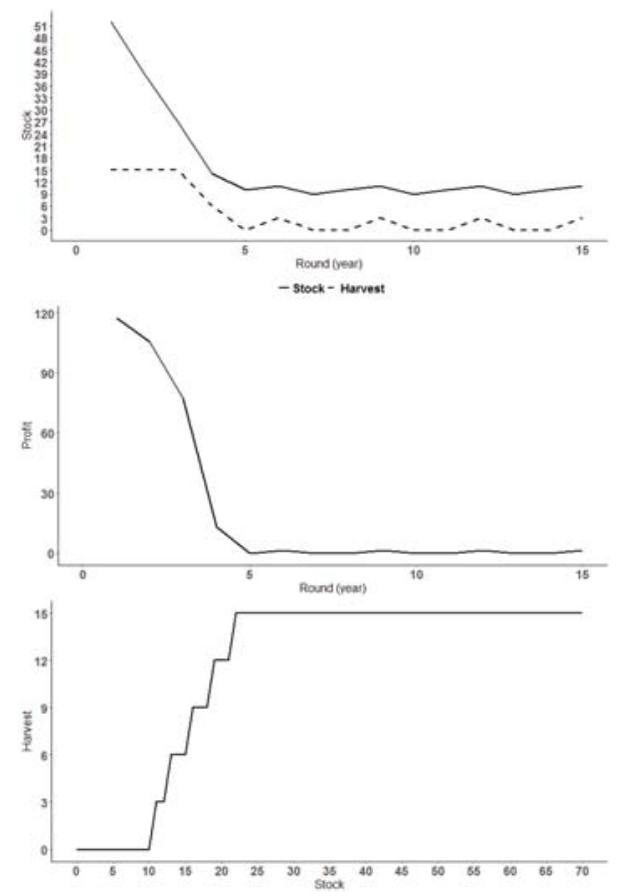

968

$$
\pi_{i, t}=(\mathrm{H} 2)
$$
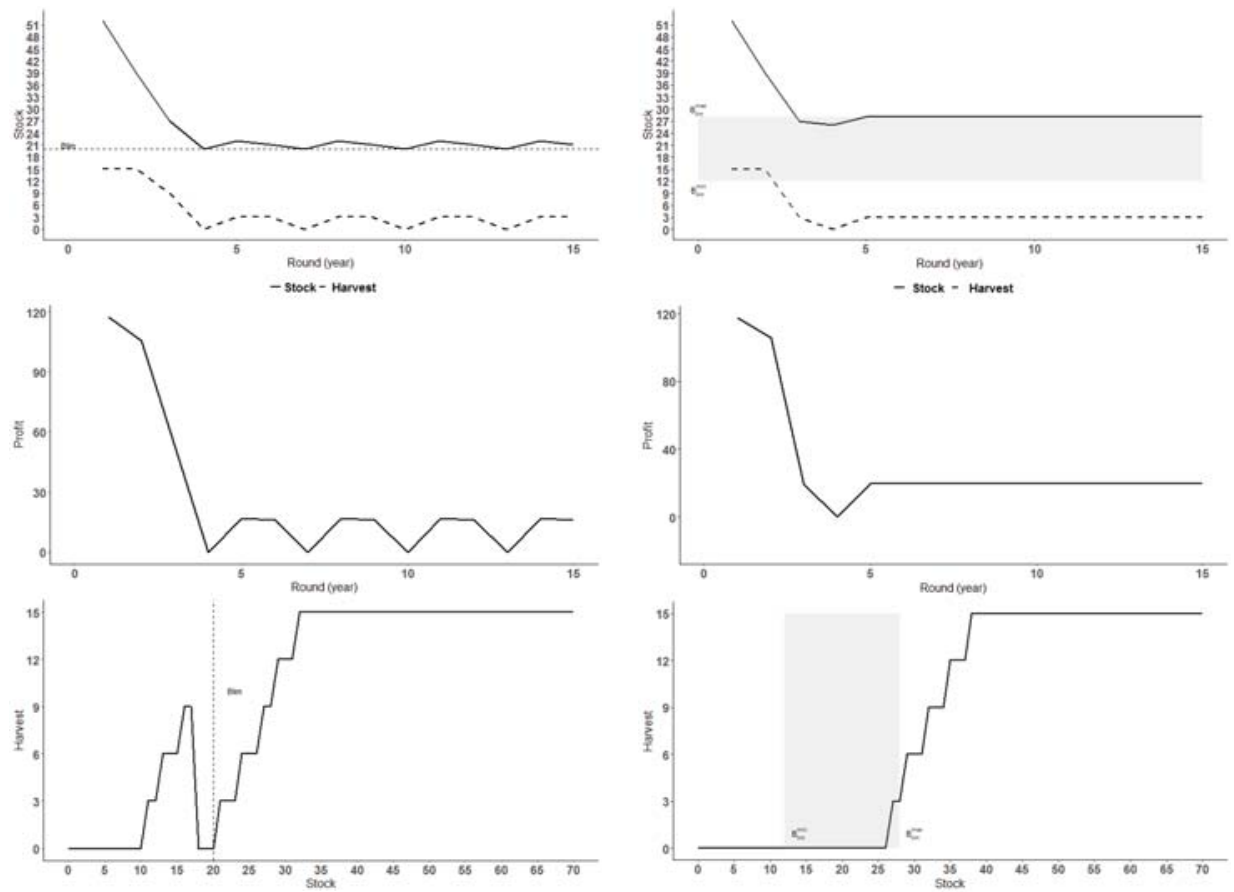


\begin{tabular}{|c|c|c|c|}
\hline & Phase 1 & Phase 2 & $\begin{array}{l}\text { p (Mann-Whitney-Wilcoxon } \\
\text { test, } \chi^{2} \text { or Fisher's exact test) } \dagger\end{array}$ \\
\hline $\begin{array}{l}\text { Average group harvest as a } \\
\text { fraction of myopic strategy }\end{array}$ & $0.68(0.67)$ & $0.67(0.74)$ & 0.92 \\
\hline Average group stock & $25.94(15.41)$ & $25.75(15.71)$ & 0.87 \\
\hline $\begin{array}{l}\text { Proportion of group crossing } \\
\text { the threshold }\end{array}$ & 0.64 & 0.64 & 1.00 \\
\hline Average group profit & $4.60(28.17)$ & $5.00(28.22)$ & 0.92 \\
\hline Average group harvest & $1.49(1.64)$ & $1.48(1.70)$ & 0.97 \\
\hline Average group pledge & $1.19(1.52)$ & $1.12(1.47)$ & 0.49 \\
\hline Average group belief error & $-0.67(2.89)$ & $-0.70(2.92)$ & 0.81 \\
\hline $\begin{array}{l}\text { Average group intended } \\
\text { behavior }\end{array}$ & $0.30(1.68)$ & $0.36(1.69)$ & 0.65 \\
\hline
\end{tabular}

Note: Standard errors in brackets.

*Indicates significance $p<0.05$, ${ }^{* *} p<0.01$ and ${ }^{* * *} p<0.001$.

T Mann-Whitney-Wilcoxon test is used to compare means across phases and $\chi^{2}$ or Fisher's exact test (depending on the case frequencies) used to compare proportions across treatments and phases (see Appendix 6 for information on statistical analysis). regression.

\begin{tabular}{lcc}
\hline \multicolumn{1}{c}{ Binomial regression models } & $\begin{array}{c}\text { Random group effect GLMM } \\
\text { regression } \\
\text { Best model }\end{array}$ & $\begin{array}{c}\text { Random group effect GLMM } \\
\text { regression } \\
\text { Best model }\end{array}$ \\
\hline Intercept & $\begin{array}{c}\text { Harvest as fraction of myopic } \\
\text { strategy }\end{array}$ & $\begin{array}{c}\text { Mean group harvest as fraction of } \\
\text { myopic strategy }\end{array}$ \\
Treatment 1 & $1.40^{* * *}(0.28)$ & $2.45^{* * *}(0.31)$ \\
Treatment 2 & $-1.32^{* * *}(0.30)$ & $-1.19^{* *}(0.48)$ \\
Biomass & $-1.39^{* * *}(0.32)$ & $-1.31^{* *}(0.51)$ \\
Player class Consensual ${ }^{+}$ & $-0.05^{* * *}(0.005)$ & $\left.-0.05^{* * *} 0.008\right)$ \\
Player class Free-rider & $0.47^{*}(0.22)$ & - \\
Player class Realistic & $1.10^{* * *}(0.18)$ & - \\
Player class Pessimistic & $0.52^{*}(0.27)$ & 0.26 \\
$\mathrm{R}^{2}$ & $0.38^{*}(0.18)$ & 578 \\
AIC/QIC & 0.27 & 34 \\
Number of clusters & 1676 & 15 \\
Clusters size & 34 & 510 \\
Observations & 45 & \\
\hline Note: Standard errors are in brackets. & 1530 & - \\
$*$ Indicates significance $\mathrm{p}<0.05, * * \mathrm{p}<0.01$ and ${ }^{* * *} \mathrm{p}<0.001$. & & \\
\hline
\end{tabular}




\section{10. Figures}

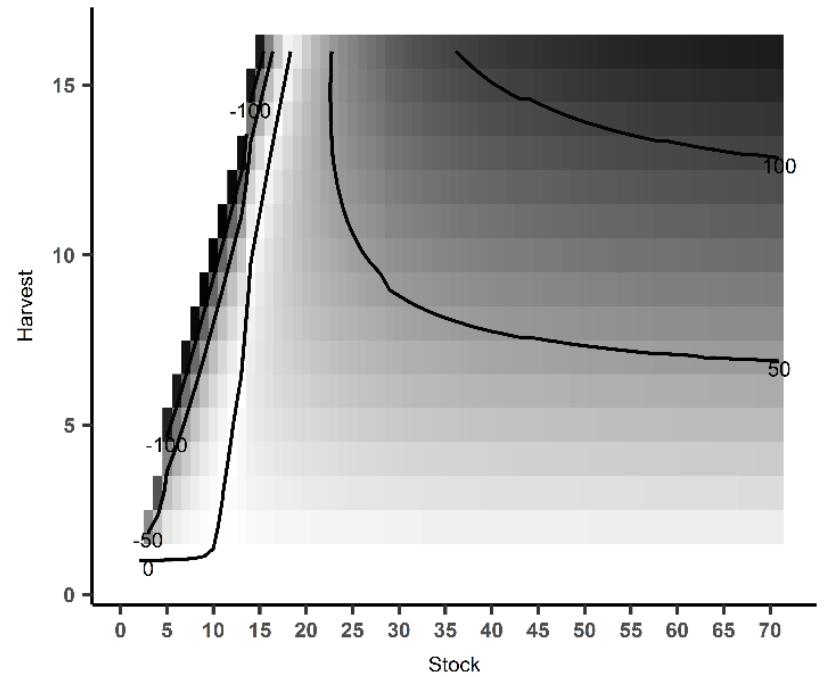

$\begin{array}{llllll}\text { Profit } \quad-100 & -50 & 0 & 50 & 100\end{array}$

976

977 Figure 1: Logistic resource growth (104 tons).

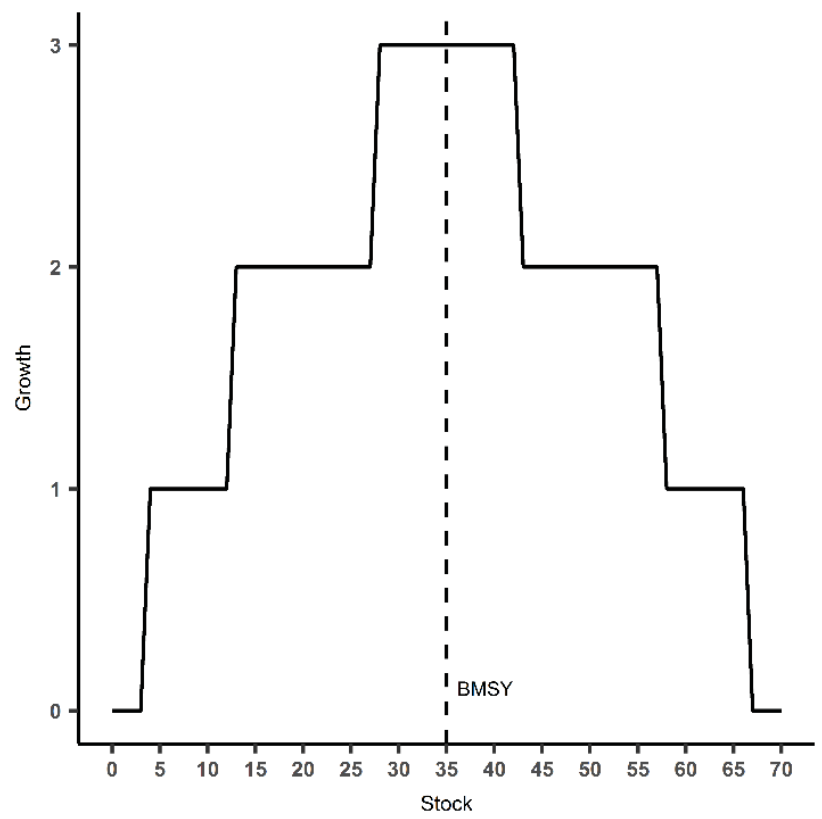

978

979 Figure 2: Profit ( $\left.10^{7} €\right)$ as a function of stock ( $10^{4}$ tons) and harvest level ( $10^{4}$ tons). 

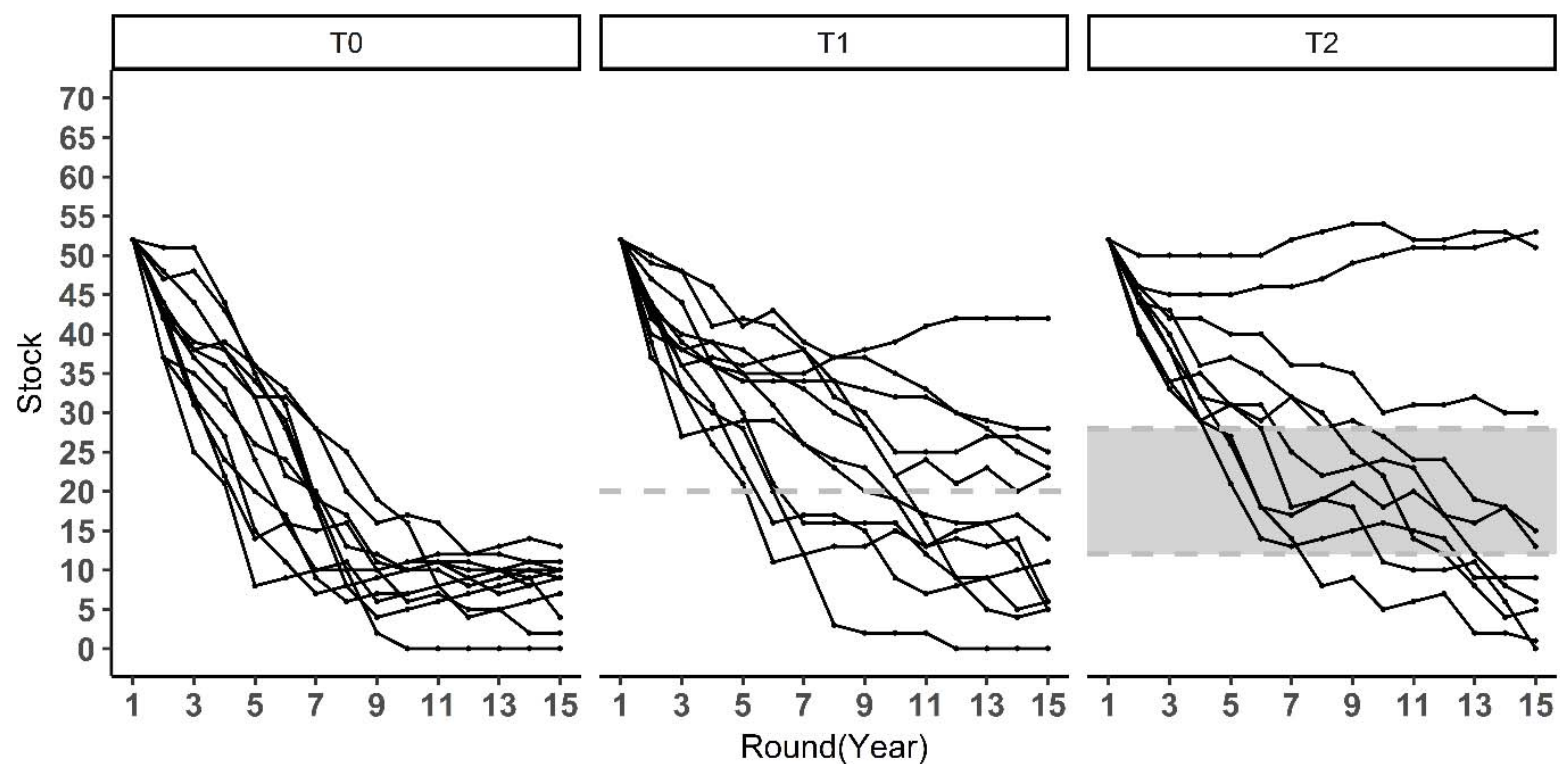

981 Figure 3: Time series of resource stock size (biomass in units) by treatments (T0, T1 and T2). The 982 grey dashed line corresponds to the threshold $\mathrm{B}_{\lim }$ in $\mathrm{T} 1$ and the shaded area to the uncertainty range around the potential value of $\mathrm{B}_{\lim }$ in $\mathrm{T} 2$.
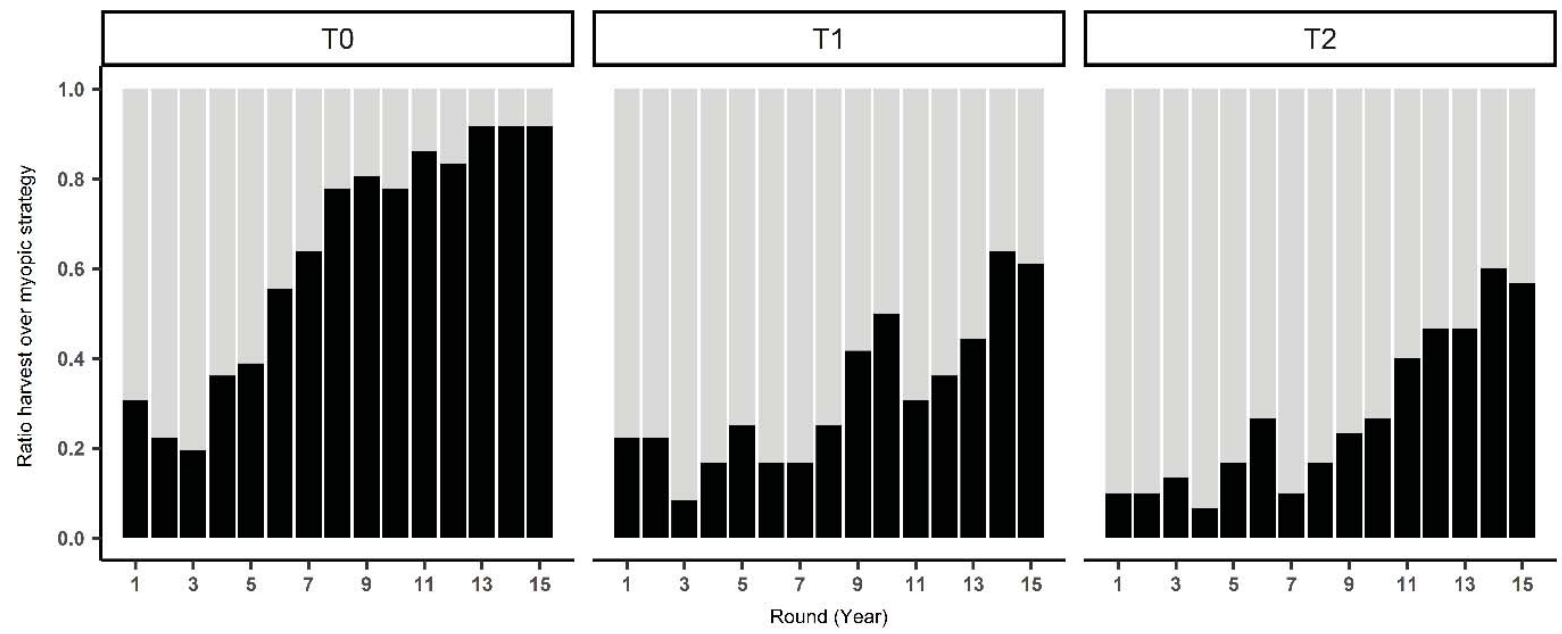

984

Figure 4: Proportion of harvest as a fraction of myopic strategy overtimes by treatments (T0, T1 and T2) summarized into a categorical variable: 'Myopic' if the ratio of the harvest choice over the myopic strategy is larger or equal to 1 and 'NonMyopic' if the ratio is smaller to 1 . 

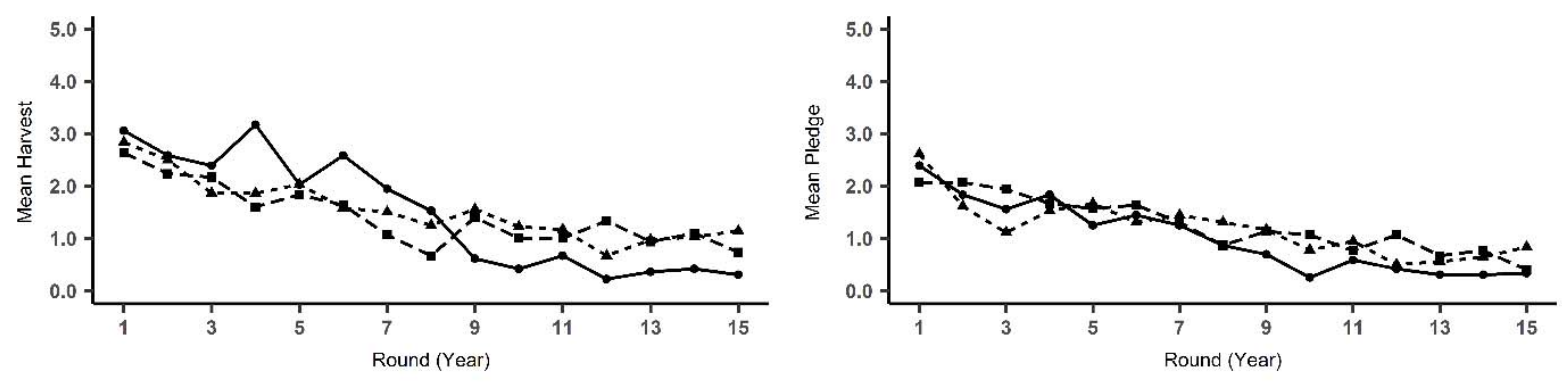

$\rightarrow$ T0 - - - T1 - - T2
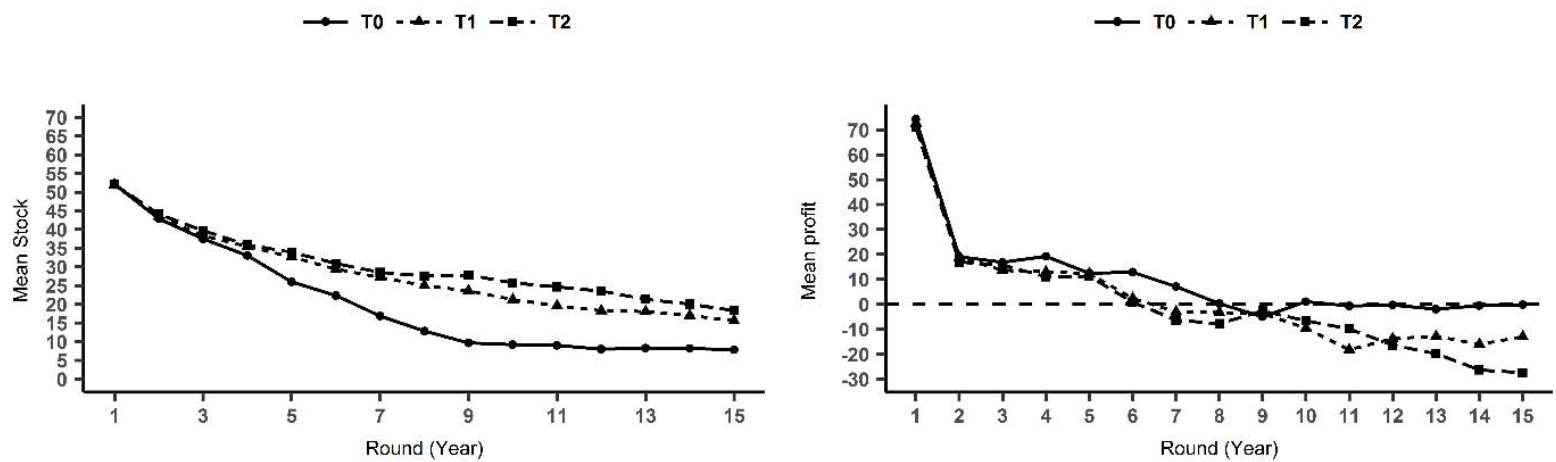

$\rightarrow$ T0 - ‥ T1 - - - T2

$\multimap$ T0 - - - T1 $\because-\mathrm{T} 2$
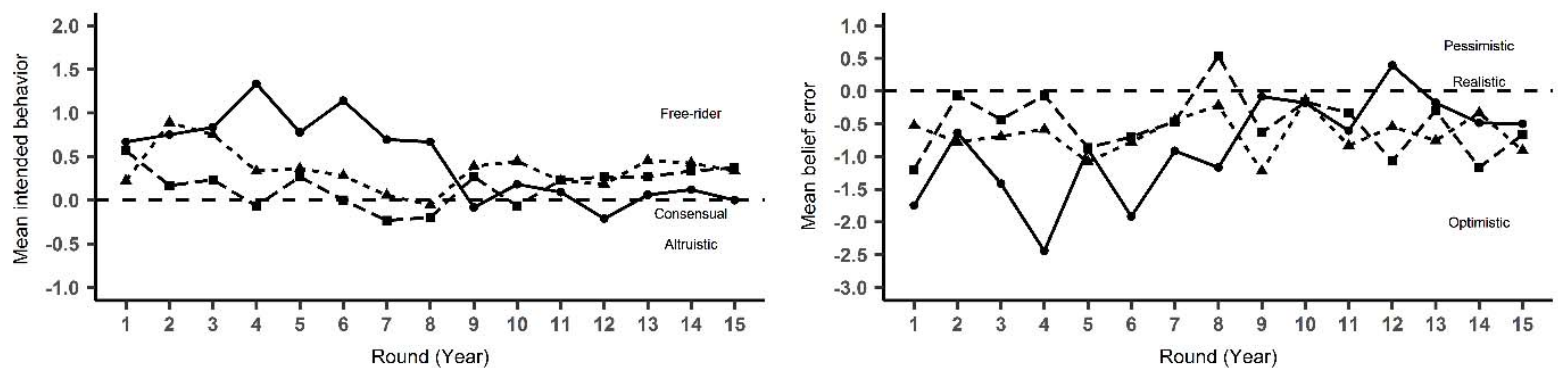

$\rightarrow$ T0 - A. T1 - - - T2

$\rightarrow$ T0 - ค. T1 -־. T2

988

989 Figure 5: Time series of mean harvest, pledge decisions and mean resulting resource stock size,

990 profit, intended behavior and belief error by treatments (T0, T1 and T2). 


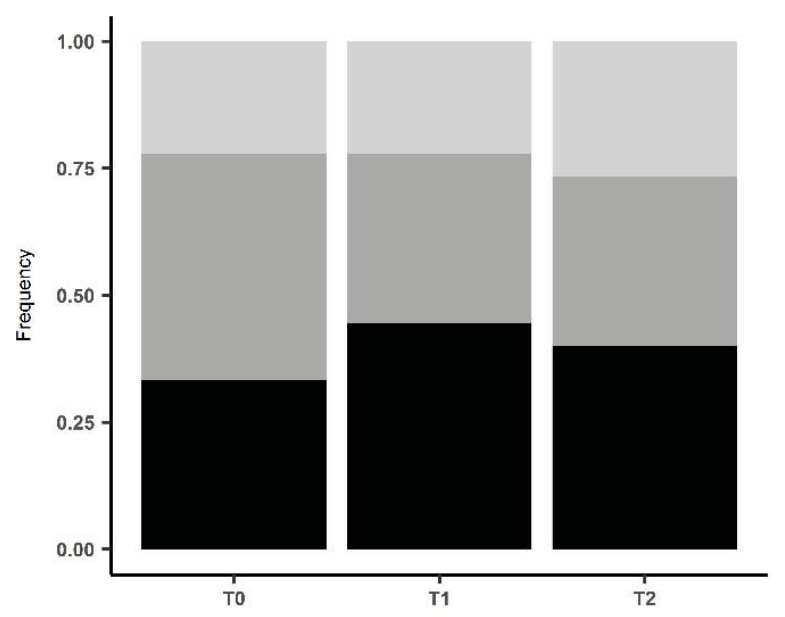

Altruistic

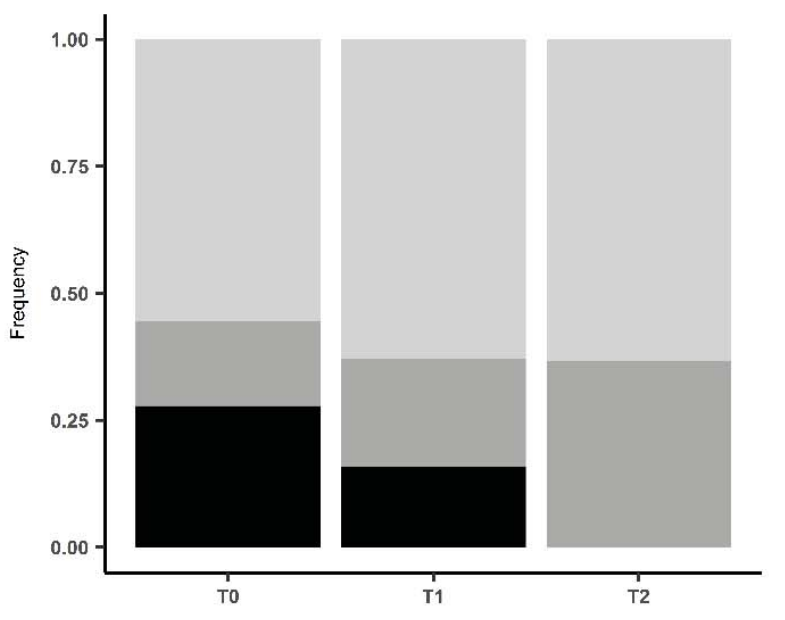

Optimistic

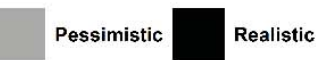

991

992 Figure 6: Frequency of subject types for the whole experiments and by treatments (T0, T1 and

993 T2). Classification of subjects based on their highest frequency belief errors (optimistic: belief < 994 other harvests, realistic: belief $=$ other harvests and pessimistic: belief $>$ other harvests) and 995 intended harvest behaviors (free-rider: harvest > pledges / (N-1), consensual: harvest = pledges 996 / (N-1) and altruistic: harvest < pledges / (N-1)). 
999 Table 1: Bioeconomic model parameters.

\begin{tabular}{llc}
\hline \multicolumn{1}{c}{ Variable } & \multicolumn{1}{c}{ Description } & Value \\
\hline $\mathrm{N}$ & Participant number & 3 \\
$\mathrm{ymax}$ & Maximum harvest $\left[10^{4} \mathrm{t}\right]$ & 5 \\
$\mathrm{p}$ & Price $\left[10^{7} € / 10^{4} \mathrm{t}\right]$ & 10 \\
$\mathrm{r}$ & Growth rate & 0.15 \\
$\mathrm{~K}$ & Carrying capacity $\left[10^{4} \mathrm{t}\right]$ & 70 \\
$\mathrm{c}$ & Cost parameter $\left[10^{7} € / 10^{4} \mathrm{t}\right]$ & 100 \\
$\alpha$ & Threshold fixed cost $\left[10^{7} \$\right]$ & 30 \\
$\mathrm{~B} \lim$ & Threshold $\left[10^{4} \mathrm{t}\right]$ & 20 \\
\hline
\end{tabular}

Table 2: Experimental design.

Treatment 0

Treatment 1

Treatment 2

\begin{tabular}{lccc}
\hline Nature of threshold & No Threhold & Blim & {$\left[B_{\lim } \min , B_{\text {lim }}\right.$ max $]$} \\
Description & Baseline treatment & $\begin{array}{c}\text { Subjects both know that } \\
\text { there is a threshold and its } \\
\text { position. }\end{array}$ & $\begin{array}{c}\text { Subjects know that there is a } \\
\text { threshold but they do not know its } \\
\text { position, only a range with equal } \\
\text { possibility. }\end{array}$ \\
$\begin{array}{l}\text { Number of groups } \\
\text { Number of subjects }\end{array}$ & 18 & 6 & 5 \\
$\begin{array}{l}\text { Number of group } \\
\text { observation }\end{array}$ & 2 & 18 & 15 \\
$\begin{array}{l}\text { Number of } \\
\text { experiments }\end{array}$ & 12 & 12 & 2 \\
\hline
\end{tabular}

1002

1003 Table 3: Description of variables used for analysis.

\begin{tabular}{|c|c|c|}
\hline Variable & Value range & Description \\
\hline $\begin{array}{l}\text { Harvest as a fraction of } \\
\text { myopic strategy }\end{array}$ & $\mathrm{R}^{+}$ & $\begin{array}{l}\text { Individual harvest decision as a fraction of the myopic } \\
\text { strategy by period. }\end{array}$ \\
\hline Crossing threshold & $0 \vee 1$ & Group crosses the threshold within 15 rounds. \\
\hline $\begin{array}{l}\text { Belief error (error in other } \\
\text { harvests level belief) }\end{array}$ & {$[-10,10]$} & $\begin{array}{l}\text { Difference between beliefs and the sum of harvest by other } \\
\text { participants by period. }\end{array}$ \\
\hline Intended behavior & {$[-5,5]$} & $\begin{array}{l}\text { Difference between harvest and symmetric harvest beliefs of } \\
\text { other participants by period (pledges/(N-1)). }\end{array}$ \\
\hline Subject type & $\begin{array}{l}\text { [optimistic, realistic, } \\
\text { pessimistic, free-rider, } \\
\text { consensual, altruistic] }\end{array}$ & $\begin{array}{l}\text { Classification of subjects based on their highest frequency } \\
\text { belief errors (optimistic: belief < other harvests, realistic: } \\
\text { belief = other harvests and pessimistic: belief > other } \\
\text { harvests) and intended harvest behaviors (free-rider: harvest } \\
\text { > pledges / (N-1), consensual: harvest = pledges / }(\mathrm{N}-1) \text { and } \\
\text { altruistic: harvest < pledges / }(\mathrm{N}-1) \text { ). }\end{array}$ \\
\hline Knowledge index ${ }^{\dagger}$ & {$[1,5]$} & Perceived understanding about the resource dynamic. \\
\hline Score test ${ }^{\dagger}$ & {$[0,3]$} & Individual score to the understanding test. \\
\hline
\end{tabular}


Table 4: Comparison of proportions and averages across treatments.

\begin{tabular}{|c|c|c|c|c|}
\hline & Treatment 0 & Treatment 1 & Treatment 2 & $\begin{array}{c}\text { p (Kruskal-Wallis test, } \chi^{2} \text { or } \\
\text { Fisher's exact test) }{ }^{\dagger}\end{array}$ \\
\hline $\begin{array}{l}\text { Average group harvest as a } \\
\text { fraction of myopic strategy }\end{array}$ & $0.81(0.54)$ & $0.65(0.80)$ & $0.53(0.72)$ & $0.074^{*}$ \\
\hline Average group stock level & $20.20(15.3)$ & $27.80(13.9)$ & 30.30 (15.8) & $0.013^{*}$ \\
\hline $\begin{array}{l}\text { Proportion of group } \\
\text { exceeding the threshold }\end{array}$ & - & 0.58 & 0.70 & 0.68 \\
\hline Average earning $[€] x$ & $4.40(4.62)$ & $2.17(4.29)$ & $2.15(3.82)$ & 0.11 \\
\hline Average group profit & $10.31(22.70)$ & $2.90(29.30)$ & $0.40(31.54)$ & $0.047^{*}$ \\
\hline Average group harvest & $1.49(1.80)$ & $1.54(1.57)$ & $1.42(1.60)$ & 0.24 \\
\hline Average group pledge & $1.02(1.48)$ & $1.20(1.50)$ & $1.26(1.50)$ & 0.32 \\
\hline Average group belief error & $-0.87(3.00)$ & $-0.66(2.90)$ & $-0.51(2.80)$ & 0.53 \\
\hline $\begin{array}{l}\text { Average group intended } \\
\text { behavior }\end{array}$ & $0.46(1.70)$ & $0.34(1.61)$ & $0.16(1.75)$ & 0.27 \\
\hline $\begin{array}{l}\text { Average pre- experimental } \\
\text { survey understanding } \\
\text { index }\end{array}$ & $3.90(1.24)$ & $3.90(1.10)$ & $4.30(0.87)$ & 0.27 \\
\hline $\begin{array}{l}\text { Average pre- experimental } \\
\text { test understanding index } x^{\dagger, r}\end{array}$ & $2.00(1.00)$ & $1.39(1.00)$ & $1.60(1.20)$ & $0.04^{*}$ \\
\hline \multicolumn{5}{|c|}{$\begin{array}{l}\text { Note: Standard errors in brackets. } \\
\text { *Indicates significance } p<0.05, * * p<0.01 \text { and }{ }^{* * *} p<0.001 \text {. } \\
\text { † Self-reported variable, obtained from pre and post-experiment survey (supplementary material Appendix C). } \\
\text { T Kruskal-Wallis test is used to compare means across treatments and } \chi^{2} \text { or Fisher's exact test (depending on the case } \\
\text { frequencies) used to compare proportions across treatments. } \\
\chi \text { Average earnings (from profits and belief elicitations) doesn't include participation fees. } \\
v \text { Average understanding index is the answer from the post-experiment survey on a five-point Likert scale. } \\
\text { Г Average pre- experimental test understanding index is the score from the } 3 \text { pre-experiment questions (supplementary } \\
\text { material Appendix C). A score of } 3 \text { indicates a perfect understanding, while a score of } 0 \text { a very weak comprehension of the } \\
\text { experiment dynamic mechanisms before clarification by the experimenter. }\end{array}$} \\
\hline
\end{tabular}

1007

1008 
1009 Table 5: Generalized Estimating Equation regression for the average probability of making a 1010 myopic harvest decision.

\begin{tabular}{lcc}
\hline \multicolumn{1}{c}{ Binomial regression models } & $\begin{array}{c}\text { GEE regression } \\
\text { Best model }\end{array}$ & $\begin{array}{c}\text { GEE regression } \\
\text { Best model }\end{array}$ \\
\hline Intercept & $\begin{array}{c}\text { Harvest as fraction of myopic } \\
\text { strategy }\end{array}$ & $\begin{array}{c}\text { Mean group harvest as } \\
\text { fraction of myopic strategy }\end{array}$ \\
Treatment 1 & $1.55^{* * *}(0.22)$ & $1.93^{* * *}(0.30)$ \\
Treatment 2 & $-0.91^{* * *}(0.16)$ & $-0.75^{* *}(0.24)$ \\
Biomass & $-0.97^{* * *}(0.17)$ & $-1.01^{* *}(0.29)$ \\
Player class Consensual ${ }^{+}$ & $-0.04^{* * *}(0.004)$ & $-0.03^{* * *}(0.008)$ \\
Player class Free-rider & $0.18(0.20)$ & - \\
Player class Realistic & $0.73^{* * *}(0.18)$ & - \\
Player class Pessimistic & $0.40 *(0.17)$ & - \\
$\mathrm{R}^{2}$ & $-0.06(0.12)$ & 0.31 \\
AIC/QIC & 0.26 & 601 \\
Correlation structure & 1810 & $\mathrm{AR} 1$ \\
Correlation parameter & $\mathrm{AR}-1$ & 0.41 \\
Scale parameter & $0.36(0.03)$ & 0.57 \\
Number of clusters & $0.59(0.03)$ & 34 \\
Clusters size & 102 & 15 \\
Observations & 15 & 510 \\
\hline
\end{tabular}

Note: Standard errors are in brackets.

*Indicates significance $p<0.05,{ }^{* *} p<0.01$ and ${ }^{* * *} p<0.001$.

tPlayer classes are characterized by both belief errors and intended behavior (harvest decisions) to others pledge (Table 3):

Optimistic; Pessimistic; Realistic and Consensual; Free rider; Altruistic. 